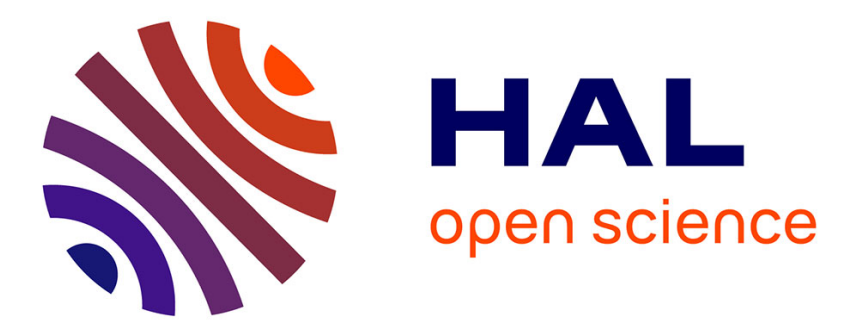

\title{
Role of the southern Indian Ocean in the transitions of the monsoon-ENSO system during recent decades
}

\author{
Pascal Terray, Sébastien Dominiak, Pascale Delécluse
}

\section{To cite this version:}

Pascal Terray, Sébastien Dominiak, Pascale Delécluse. Role of the southern Indian Ocean in the transitions of the monsoon-ENSO system during recent decades. Climate Dynamics, 2005, 24 (2-3), pp.169-195. 10.1007/s00382-004-0480-3 . hal-00124971

\section{HAL Id: hal-00124971 \\ https://hal.science/hal-00124971}

Submitted on 27 Jun 2016

HAL is a multi-disciplinary open access archive for the deposit and dissemination of scientific research documents, whether they are published or not. The documents may come from teaching and research institutions in France or abroad, or from public or private research centers.
L'archive ouverte pluridisciplinaire HAL, est destinée au dépôt et à la diffusion de documents scientifiques de niveau recherche, publiés ou non, émanant des établissements d'enseignement et de recherche français ou étrangers, des laboratoires publics ou privés. 


\title{
Role of the southern Indian Ocean
}

\section{in the transitions of the monsoon-ENSO system during recent decades}

\author{
By \\ P. Terray $(1,2)$, S. Dominiak (1), P. Delecluse $(1,3)$ \\ (1) Laboratoire d'Océanographie Dynamique et de Climatologie, Paris, France
}

(2) Université Paris 7, Paris, France

(3) Laboratoire des Sciences du Climat et de l'Environnement, Gif-sur-Yvette, France

Submitted to Climate Dynamics February, 2004

Revised June, 2004 


\begin{abstract}
The focus of this study is to document the possible role of the southern subtropical Indian Ocean in the transitions of the monsoon-ENSO system during recent decades.

Composite analyses of Sea Surface Temperature (SST) fields prior to El Niño-Southern Oscillation (ENSO), Indian Summer Monsoon (ISM), AUstralian Summer Monsoon (AUSM), Tropical Indian Ocean Dipole (TIOD) and Maritime Continent Rainfall (MCR) indices reveal the South East Indian Ocean (SEIO) SSTs during late boreal winter as the unique common SST precursor of these various phenomena after the 1976-1977 regime shift. Weak (strong) ISMs and AUSMs, El Niños (La Niñas) and positive (negative) TIOD events are preceded by significant negative (positive) SST anomalies in the SEIO, off Australia during boreal winter. These SST anomalies are mainly linked to subtropical Indian Ocean dipole events, recently studied by Behera and Yamagata (2001). A wavelet analysis of a February-March SEIO SST time series shows significant spectral peaks at 2 and 4-8 years time scales as for ENSO, ISM or AUSM indices. A composite analysis with respect to February-March SEIO SSTs shows that cold (warm) SEIO SST anomalies are highly persistent and affect the westward translation of the Mascarene high from austral to boreal summer, inducing a weakening (strengthening) of the whole ISM circulation through a modulation of the local Hadley cell during late boreal summer. At the same time, these subtropical SST anomalies and the associated SEIO anomalous anticyclone may be a trigger for both the wind-evaporation-SST and wind-thermocline-SST positive feedbacks between Australia and Sumatra during boreal spring and early summer. These positive feedbacks explain the extraordinary persistence of the SEIO anomalous anticyclone from boreal spring to fall. Meanwhile, the SEIO anomalous anticyclone favors persistent southeasterly wind anomalies along the west coast of Sumatra and westerly wind anomalies over the western Pacific, which are well-known key-factors for the evolution of positive TIOD and El Niño events, respectively. A correlation analysis supports these results and shows that SEIO SSTs in February-March has higher predictive skill than other well-established ENSO predictors for forecasting Niño3.4 SST at the end of the year. This suggests again that SEIO SST anomalies exert a fundamental influence on the transitions of the whole monsoon-ENSO system during recent decades.
\end{abstract}




\section{Introduction}

In recent times, the Indian Ocean has come into the limelight as an important driving factor in low-frequency variations of the tropical climate, contrasting with the classical view that the Indian Ocean is only a passive element in the tropical system, essentially controlled by El Niño through an atmospheric bridge (Klein et al., 1999; Alexander et al. 2002; Lau and Nath, 2000, 2003), and by the Asian summer monsoon via air-sea fluxes associated with the monsoon flow (Webster et al., 1998).

As a first illustration, the study of the relationship between Indian Ocean Sea Surface Temperature (SST) anomalies and the variability of the Indian Summer Monsoon (ISM) is still a controversial matter (Webster et al., 1998). However, many recent modelling and observational studies have suggested stronger relationships between tropical Indian Ocean SST anomalies and anomalous ISMs (Harzallah and Sadourny, 1997; Chandrasekar and Kitoh, 1998; Clark et al., 2000; Li et al., 2001b; Meehl and Arblaster, 2002a,b) than suggested in earlier studies.

As a second example, the actual mechanism by which the El Niño-Southern Oscillation (ENSO) signal is propagated is, so far, not well understood and several studies have pointed to an eastward phase propagation of zonal wind anomalies from the Indian Ocean toward the western equatorial Pacific Ocean in the surface wind field for triggering El Niño events (Barnett, 1983; Glutzer and Harrison, 1987; Ropelewski et al., 1992; Clarke and Van Gorder, 2003). This stresses the role of coupled air-sea processes in the eastern equatorial Indian Ocean in El Niño onset.

In the last decade, a great deal of attention has also been paid to local air-sea interaction in the tropical Indian Ocean during boreal fall (Saji et al., 1999; Webster et al., 1999). Saji et al. (1999) have proposed the concept of the Tropical Indian Ocean Dipole (TIOD) mode for this air-sea coupled pattern, extending earlier works by Reverdin et al. (1986), Nicholls (1989) and Drosdowsky (1993). It is natural to ask if TIOD variability is an inherent Indian Ocean mode (Anderson, 1999). Some authors argue that TIOD events are triggered by ENSO (Allan et al., 2001; Baquero-Bernal and Latif, 2002; Hendon, 2003, Shinoda et al., 2004), others claim that they are the manifestation of a coupled ocean-atmosphere instability inherent to the Indian Ocean-monsoon system (Webster et al., 1999; Iizuka et al., 2000; Rao et al., 2002; Yamagata et al., 2002; Ashok et al., 2003) and that both phenomena interact with each other (Saji and Yamagata, 2003, Behera and Yamagata, 2003; Saji and Yamagata, 2004). 
The Tropospheric Biennial Oscillation (TBO) is defined as the tendency for strong ISMs to be followed by a strong North AUstralian Summer Monsoon (AUSM) six months later and by a relatively weak ISM one year later (Yasunari, 1991; Meehl, 1987, 1997). In the framework of the TBO, Meehl and al. (2003) have described the strong interactions existing between SST, heat content and wind anomalies within the tropical Pacific and Indian oceans and rainfall over Asia and Australia. Meehl and Arblaster (2002a,b) and Meehl et al. (2003) have suggested that ENSO, the ISM, AUSM and TIOD are all integral parts of the TBO. Moreover, Meehl and Arblaster (2002a,b) have pointed out that the TBO transitions are related to three factors: $500 \mathrm{hPa}$ height-Asian land temperature, and tropical Indian and Pacific SSTs. Coupled air-sea processes in the tropical Indian Ocean again play an important role in forming and sustaining SST anomalies in the whole Indo-Pacific sector. Moreover, there is now pervasive evidence that the Indian Ocean plays a critical role in the TBO transitions (Yu et al., 2003). It has even been suggested that the origin of the TBO may arise from coupled processes within the tropical Indian Ocean (Chang and Li, 2000; Li et al., 2001a). Finally, Wang et al. (2003) argued that an anomalous South East Indian Ocean (SEIO) anticyclone in boreal summer and fall plays, in conjunction with the anomalous West Pacific anticyclone (Lau and $\mathrm{Wu}, 2001$ ) in winter and spring, a fundamental role in the evolution of the AsianAustralian monsoon system. They suggested that local air-sea interactions are responsible for the persistence of this anomalous circulation. Collectively, these studies are important because they suggest that there are coupled modes of variability inherent to the Indian Oceanmonsoon system, independent of ENSO to some extent, which may be used to increase our ability to predict tropical variability on interannual time scales.

While much has been learned about the tropical Indian Ocean and its relationships with ENSO, the Asian monsoon or the TBO in the above studies, less is known about the interannual variability in the southern Indian Ocean. The subtropical Indian Ocean and its relationship with tropical dynamics have been much less studied, in contrast with Pacific extra-tropical latitudes, whose links with ENSO have been extensively explored (Wallace and Gutzler, 1981; Gershunov and Barnett, 1998; Lu 2001; Pierce, 2002; Kidson and Renwick, 2002; among many others). However, some studies have suggested that the subtropical Indian Ocean plays an important role in modulating local climate dynamics. Nicholls (1989) identified an anomalous SST pattern in the south Indian Ocean during austral winter which is largely independent of ENSO and influences the Australian winter rainfall (June-August). Drosdowsky (1993) and Drosdowsky and Chambers (2001) have also studied the connections between southern Indian Ocean SST and seasonal rainfall in Australia during other seasons. 
Behera and Yamagata (2001) described the existence of a coupled air-sea pattern of variability within the southern subtropical Indian Ocean during boreal winter. Moreover, they stressed the role of this SST dipole mode (warmer water to the west, colder to the east) in summer rainfall variability over central southern Africa. Reason (2002) forced an atmospheric general circulation model with positive SST anomalies in the southwest Indian Ocean and negative SST anomalies in the southeast Indian Ocean. The results show increased rainfall over southeastern Africa, a result consistent with previous modeling and observational studies by Goddard and Graham (1999), Reason and Mulenga (1999) and Behera and Yamagata (2001). Fauchereau et al. (2003) have linked this southern Indian Ocean SST dipole with a similar mode of variability in the southern Atlantic Ocean. More recently, Terray et al. (2003a) have provided evidence of a link between this SST dipole (or anomalous gradient) in the south Indian Ocean during boreal winter and ISM variability.

The current paper further explores the relationship between the southern subtropical Indian Ocean and the Indo-Pacific tropical climate. The focus of the study is to document the possible role of the southern subtropical Indian Ocean in the transitions of the whole (AsianAustralian) monsoon-ENSO system. This is a follow-up of the earlier study by Terray et al. (2003a), which suggests that southern Indian Ocean SST acts as a major boundary forcing for the ISM system, a key-element in the TBO. Our hypothesis is that SEIO SST anomalies during boreal winter may trigger coupled air-sea processes in the tropical eastern Indian and western Pacific oceans during the following boreal spring, summer and fall which are fundamental for the transitions of the whole monsoon-ENSO system. We restrict our analysis to the 1977-2001 period, since it is well known that significant long-term changes in the distribution of Indo-Pacific SST and tropical teleconnection patterns occurred around 19761977 (Nitta and Yamada, 1989; Kumar et al., 1999, Clark et al., 2000; Wang and An, 2001; Kinter et al., 2002; Wu and Wang, 2002). Analysis of the implication of the 1976-77 climate shift on the relationship between SEIO SST and the monsoon-ENSO system is left for further study.

The paper is composed of six sections and an appendix. Section 2 describes the observational data and the methods used in our analysis. Section 3 presents composite patterns of SST anomalies in the February-March season (e.g., just before the transition of the monsoonENSO system in the Pacific Ocean) associated with extreme phases of ENSO, TIOD, ISM, AUSM and a Maritime Continent Rainfall (MCR) index. Then, in Section 4, we will show the 
composite atmospheric and SST evolution during a one-year period associated with cold and warm SEIO SSTs, in order to document the role of these SST anomalies in the evolution of the whole monsoon-ENSO system. In Section 5, we quantitatively assess the predictive skill associated with a SEIO SST index through a correlation analysis and compare its strength to other well-established ENSO precursors. We summarize our results and discuss them in the context of previous works in Section 6. Finally, all the acronyms used in the paper are listed and defined in an appendix.

\section{Data and methods}

The data used to examine the atmospheric circulation are monthly Sea Level Pressure (SLP), 850 and $200 \mathrm{hPa}$ winds, vertical velocity (omega) and latent heat flux anomalies for the period 1977-2001 computed from the National Center for Environmental PredictionNational Center for Atmospheric Research (NCEP-NCAR) reanalysis outputs (Kalnay et al., 1996). We used the updated version of the reanalysis in which the error associated with the processing of Television Infrared Observational Satellite Operational Vertical Sounder data, occurring from March 1997 has been corrected (see http://www.noaa.ncdc.gov/cdc/reanalysis/problems.shtml).

The monthly SST data, for the same 25 years, used in this study come from the Extended Reconstruction of global SST (ERSST) dataset, developed on a $2^{\circ} \mathrm{X} 2^{\circ}$ grid, by Smith and Reynolds (2003). Upper ocean monthly data are from the University of Maryland Simple Ocean Data Assimilation (SODA; Carton et al., 2000a,b). The depth of the main thermocline (estimated using the depth of the $20^{\circ} \mathrm{C}$ isotherm) used in Section 5 is computed from the SODA product.

Finally, we also use 23 years (1979-2001) of observed rainfall data from the gridded Climate prediction center Merged Analysis of Precipitation (CMAP) dataset (Xie and Arkin, 1997). We take advantage of the recently updated version of the CMAP dataset because older versions are flawed in several ways (see http://www.noaa.ncdc.gov/cdc/data_cmap.html). Most rainfall indices computed in this paper are from the CMAP dataset. However, the area weighted monthly rainfall series for all India carefully prepared by Parthasarathy et al. (1995) has been used to assess ISM rainfall variability over the Indian subcontinent.

Simple composite and correlation analyses have been used to assess the transitions of the monsoon-ENSO system. The significance of the composite patterns has been assessed with the method of Terray et al. (2003a). Briefly, this method determines the areas in the 
composite that depart significantly from the background variability in the available data. Note that we do not show differences between positive (or strong) and negative (or weak) events in our composite analyses. Studying such differences allows a compact presentation of the results, but implies symmetry between positive and negative events, which is not verified in many cases, and a loss of information, which is rather difficult to evaluate (Larkin and Harrison, 2002).

The statistical significance of cross-correlation coefficients depends on the length of the time series, the autocorrelation characteristics of each time series involved and the smoothing applied. None of the time series used in this study was smoothed. Moreover, all the crosscorrelation coefficients presented here are based on yearly sampled series (the time interval between two observations is one year) showing insignificant lag-1 autocorrelations. This is illustrated in Figure 11 for the (February-March) Niño3.4 and SEIO SST time series. Thus, the confidence level of the observed correlations has been evaluated by a standard two tail $t$ test.

\section{ENSO, TIOD, ISM, AUSM and MCR SST composites}

A simple method for characterizing a complex phenomenon such as the monsoon-ENSO system is to reduce it to a small number of indices. As an illustration, Meehl et al. (2003) used the time series of area-averaged precipitation for the ISM as an index for the whole TBO system. Following Webster et al. (2002) and Meehl et al. (2003), the monsoon-ENSO or TBO systems encompass the AUSM, ISM, MCR, ENSO and TIOD events. However, AUSM, ISM, ENSO and TIOD events are not always synchronized (Webster et al., 1998; Behera and Yamagata, 2003, Ashok et al., 2003). Moreover, significant precursors for anomalous AUSMs and ISMs, ENSO and TIOD events may differ considerably. In view of these considerations, major components of the monsoon-ENSO system have been identified by different indices and SST composite fields for all these different indices will be presented in this section. The different indices used in our composite analyses and the selected extreme years of theses indices are presented in Table 1.

The area-averaged SST anomaly in the eastern tropical Pacific Niño3.4 area $\left(5^{\circ} \mathrm{N}\right.$ $5^{\circ} \mathrm{S} / 170^{\circ} \mathrm{W}-120^{\circ} \mathrm{W}$ ) has been used as an ENSO index. The Niño3.4 index has been computed from the ERSST dataset. The criterion for El Niño (La Niña) years is defined by the 5-month running mean averaged Niño3.4 SST anomaly exceeding $+0.5^{\circ} \mathrm{C}\left(-0.5^{\circ} \mathrm{C}\right)$ threshold for six 
consecutive months. ENSO years determined in this way are in agreement with Trenberth (1997), except that 1997 (1998) has been added as an El Niño (La Niña) event. One purpose of this study is to identify ENSO precursors. Thus, it seems relevant to consider only the onset year of each event in computing the composites. For instance, 1991 is a well-known protracted El Niño event, and Trenberth (1997) distinguishes three onset years for it (1991, 1993 and 1994). Following the recent work of Van Loon et al. (2003), 1993 did not qualify as an El Niño event, but 1994 does. Consequently, 1991 and 1994 are retained as onset years in the present analysis. There are finally six El Niño and four La Niña (onset) years in the 19772001 period (Table 1).

TIOD events reach maximum amplitude during September-November (Saji et al., 1999; Saji and Yamagata, 2003). The canonical TIOD SST pattern is characterized by SST anomalies of opposite sign in the western (WTIO: $50^{\circ} \mathrm{E}-70^{\circ} \mathrm{E} / 10^{\circ} \mathrm{N}-10^{\circ} \mathrm{S}$ ) and eastern (ETIO: $90^{\circ} \mathrm{E}$ $\left.110^{\circ} \mathrm{E} / 10^{\circ} \mathrm{S}-0\right)$ tropical Indian Ocean during boreal fall. The WTIO and ETIO time series have also been computed from the ERSST dataset. Following Saji et al. (1999), we used the difference between WTIO and ETIO SST anomalies as a TIOD index. This time series is related to the anomalous SST gradient across the equatorial Indian Ocean. During boreal fall, the SST mean gradient across the equatorial Indian Ocean is associated with cooler SST in the west and warmer in the east. Thus, a positive TIOD index indicates a weaker or reversed equatorial SST gradient. It is interesting to note that the TIOD index is dominated by the ETIO time series during the peak season of TIOD events because the September-OctoberNovember standard deviation of ETIO SST time series (0.41) is twice the standard deviation of the WTIO SST time series (0.21). Positive (negative) TIOD events are defined in terms of September-October-November TIOD index exceeding 1 standard-deviation above (below) the mean. Using this criterion, there are four positive and three negative TIOD events in the 1977-2001 period (Table 1).

As illustrated in Terray et al. (2003a), interannual variability of ISM rainfall and dynamical indices for the traditional summer season (June-September) are strongly influenced by rainfall and circulation anomalies observed during the Late ISM (August-September). In view of these results, we computed both ISM and Late ISM composites with the help of the AIRI. Classification of weak (strong) ISM and Late ISM years are made when the standardized ISM and Late ISM indices are $<-1(>1)$, respectively. There are five strong and five weak ISM years, and, four strong and five weak Late ISM years during the 1977-2001 period (Table 1). 
The AUSM's relation with El Niño events has been much studied (McBride and Nicholls, 1983; Drosdowsky and Williams, 1991). Moreover, interactions between the AUSM, ISM, TIOD and ENSO have been proven many times (Webster et al., 2002; Meehl et al., 2003, Wang et al., 2003; Ashok et al., 2003). This justifies the inclusion of AUSM SST composites in this study. For this purpose, we used the time series of area-averaged precipitation for the AUSM (December-January-February, $1979-2001,20^{\circ} \mathrm{S}-5^{\circ} \mathrm{N}, 100^{\circ}-150^{\circ} \mathrm{E}$ ) defined in previous TBO studies (Meehl and Arblaster, 2002a), and a threshold of one standard deviation. This choice leads to the definition of six strong and four weak AUSM years (Table 1).

Finally, MCR is a key factor for the monsoon-ENSO system (Terray et al., 2003b) and relationships between ENSO or TIOD events and rainfall over Indonesia have been extensively studied (Saji et al., 1999; Hendon, 2003; McBride et al., 2003). Thus, we found it relevant to compute an MCR index as the area-averaged precipitation over the domain $6^{\circ} \mathrm{S}$ $6^{\circ} \mathrm{N}, 111^{\circ}-141^{\circ} \mathrm{E}$ from June to September, as used in Terray et al. (2003b). Extreme years for this MCR index are defined in a similar way as for the ISM or AUSM indices (Table 1).

The transitions of the monsoon-ENSO system in the Pacific basin occur during boreal spring in association with the so-called predictability barrier (Yasunari, 1991; Webster and Yang, 1992; Torrence and Webster, 1998). This is related to the onset time of El Niño events, which is either spring (April or May) or summer (July or August) as shown by Xu and Chan (2001). Thus, we have to examine seasons prior to the end of the austral summer (March) in order to identify common precursors that set the stage for the next phase of the monsoon-ENSO system during the following 1-yr period. In view of this, February-March seems to be a relevant starting point for the SST composite analyses based on the anomalous (Late) ISM, AUSM, MCR, ENSO and TIOD years. ISM onset occurs in May-June and TIOD events peak during boreal fall. Consequently, February-March SST anomalies will provide information on what happens, respectively, three to seven months before anomalous (Late) ISMs and TIOD events. The AUSM index is computed for December-January-February and our FebruaryMarch SST composite fields for this index will give information on what happened one year before anomalous AUSMs. The February-March standardized SST composite fields over the Indian and Pacific oceans for the anomalous MCR, AUSM, ISM, Late ISM, ENSO and TIOD years are presented in Figures 1,2 and 3. Gridpoint tests with a 90\% confidence level have also been performed on all fields and are shown by shading in Figures 1,2 and 3. 
For February-March prior to El Niño (La Niña) events, there are anomalously cold (warm) SSTs in the equatorial central and eastern Pacific and a residual warm (cold) horseshoe pattern over the west and extra-tropical Pacific Ocean (Figs. 1a,b). These findings verify that February-March season is just before the growth of ENSO events in the Pacific as anticipated above. The merit of using six indices associated with the whole monsoon-ENSO system is to identify the common precursors for the various components of such complex phenomenon without making any a priori assumption about the degree of dependence of these various components. As an illustration, a significant feature is observable on almost all SST composite fields of Figures 1, 2 and 3. Cooler (warmer) SSTs in the southeast Indian Ocean and warmer (cooler) SSTs in the southwest Indian Ocean are significant precursors for weak (strong) ISMs, Late ISMs, AUSMs, MCRs, El Niño (La Niña) and positive (negative) TIOD events. Of course, there is a certain amount of variability in both the location and amplitude of the warm and cool poles for each of the composite analyses, but this SST dipole pattern is reminiscent of the subtropical SST dipole events identified by Drosdowsky (1993) and, Behera and Yamagata (2001). A closer inspection of the composite fields indicates that the pole located in the SEIO off western Australia is by far the most important both in terms of statistical significance and spatial extent. We can delimit a geographical domain $72^{\circ}-122^{\circ} \mathrm{E}$, $4^{\circ} \mathrm{S}-26^{\circ} \mathrm{S}$, which shows up on almost all the composite maps. This domain is indicated by a black frame in Figure 3d. Consequently, we computed a February-March SST anomalies time series area-averaged over this domain in order to obtain a SST SEIO index (Fig. 4). It is noteworthy that the wavelet analysis of the SEIO index shows significant spectral peaks at TBO time scale both before and after the 1976-1977 climatic shift. Longer time scales (4-8 years) are also detected in this time series suggesting ENSO variability. Interestingly, the wavelet spectrum also suggests a continuous shortening of the period of this ENSO oscillation from 1965 till the end of the record in a such a way that TBO and ENSO periodicities are virtually indistinguishable during the last decade (Fig. 4). Thus, this wavelet analysis supports the results of the previous composite analyses in suggesting that February-March SEIO SSTs are an integral part of the TBO system.

Figure 2 corroborates the previous work by Terray et al. (2003a), who demonstrated that there are statistical relationships between SEIO SST variability in boreal winter (associated with subtropical SST dipole events) and anomalous (Late) ISMs. However, their results were derived from the 1948-1998 period and they did not discuss the impact of the 1976-1977 
climatic shift on the SEIO-ISM relationship. Thus, it is worth mentioning that both ISM and Late ISM indices still have a strong and significant relationship with SEIO SSTs during the 1977-2001 time interval. This remarkable feature demonstrates the sensitivity of the ISM circulation and rainfall over India to SEIO SST anomalies. Furthermore, Terray et al. (2003a) pointed out that the Late ISM is more affected by the anomalous state of ENSO in the previous winter than the ISM as a whole, particularly for the strong monsoons. This seems to be also true for recent decades (Fig. 2).

Surprisingly, no other common SST precursors show up on the (Late) ISM, AUSM, MCR, ENSO and TIOD SST composites. Some areas exhibit more significant anomalies in a particular composite analysis, but they do not occur in all cases. For example, strong anomalies are found in the Bay of Bengal in February-March before strong Late ISMs (Fig. 2d) or negative TIOD events (Fig. 1d), but they do not emerge on La Niña or strong MCRs events (Figs. 1b and 3d). Interestingly, SST anomalies in the Pacific Ocean are much weaker. Figure 1 suggests two other SST dipole anomalies in the north and south subtropical Pacific as precursors of ENSO events. However, these SST dipole anomalies are absent on TIOD or ISM SST composites. Moreover, these SST dipole anomalies are only marginally significant compared to SEIO SST anomalies on both the El Niño and La Niña SST composites. Thus, SEIO is not always the strongest precursor area for each phenomenon taken separately, but is the best one for the whole ENSO-monsoon system.

The obvious question that then arises is the following. Why and how may the whole ENSOmonsoon system be sensitive to SST forcing in the SEIO during boreal winter, in such way that anomalous ISMs, AUSMs, MCRs, TIOD and ENSO events are all preceded by SST variability over the southern Indian Ocean? Additionally, our statistical tests suggest that this SEIO SST forcing is robust and represents the most important precursor of the monsoonENSO system in the whole Indo-Pacific SST forcing field, just before the growth of ENSO events. Particular attention is focused on this SEIO SST forcing in the next section.

\section{Composite analysis of cold and warm SEIO SST years}

In this section, we examine the evolution of atmospheric and SST anomaly patterns associated with cold and warm SEIO SSTs during boreal winter. Given that southern Indian Ocean dipole events reach a maximum in February-March and are phase-locked to the annual 
cycle (Behera and Yamagata, 2001), we again use a composite analysis for this purpose. The cold and warm extreme values of the February-March SST SEIO index (above or below a 0.5 standard-deviation threshold; full details in Table 1) were used to generate bimonthly SST, wind ( 850 and $200 \mathrm{hPa})$, SLP, omega (500 and $300 \mathrm{hPa}$ ) and latent heat flux composite fields for the following 1-yr period during the 1977-2001 time interval (Figs. 5-10). The wind composite maps shown in Figures 6,7 and 10 are masked to exhibit only wind anomalies that exceed the $90 \%$ confidence level. Finally, it is worth mentioning that the results of this composite analysis are robust against a strengthening of the threshold or the exclusion of the exceptional 1997 El Niño event from the cold SEIO SST years.

\section{a. Cold SEIO SST years}

First focusing on cold SEIO SST composites, we observe in February-March an anomalous subtropical SST gradient (or dipole mode) in the southern Indian Ocean with cool water in the east and warm in the west (Fig. 5a). Cold SST anomalies cover a large area in the eastern Indian Ocean extending southward off Australia (reaching $45^{\circ} \mathrm{S}$ ), northward into the Bay of Bengal and westward in the vicinity of New Guinea and the Maritime Continent. Significant warm anomalies are also found southeast of Madagascar. It is of interest that the response in the southwest Indian Ocean to the cold SEIO SST anomaly is of opposite sign although of smaller amplitude. This provides evidence of the physical nature of the SST dipole pattern in the southern Indian Ocean during austral summer. The February-March surface wind and omega anomalies patterns for the cold SEIO SST years show large and significant anomalies in the central south Indian Ocean (Fig. 6a). These anomalous patterns suggest that the Mascarene high is enhanced during February-March. Moreover, this anticyclonic anomaly is also observed at higher levels (Fig. 7a). Southeast of this anticyclonic anomaly, the total surface wind speed increases as the February-March mean $850 \mathrm{hPa}$ wind is southeasterly off Australia, thereby increasing evaporation and vertical mixing. The anomalous anticyclone also reduces the cloud cover and increases the downward solar radiation to the west. In other words, this suggests that positive SST dipole events arise out of surface wind forcing via changes in latent heat flux, upper ocean mixing and Ekman transport (Behera and Yamagata, 2001). Negative omega anomalies (anomalous ascent) are observed at 500 and $300 \mathrm{hPa}$ over the Philippine Sea and the Pacific Ocean warm pool (Figs. 6a and 7a). Meanwhile, there are positive omega values (anomalous subsidence) over East Asia. The significant anomalous northerlies off the East Asian coast, the significant northwesterly wind 
anomalies along the west coast of Sumatra and the westerly wind anomalies in the western equatorial Pacific at $850 \mathrm{hPa}$ (Fig. 6a) are dynamically consistent with this meridional structure, as are the $200 \mathrm{hPa}$ southeasterly wind anomalies linking anomalous ascent over the western Pacific to anomalous sinking over east Asia around $20^{\circ} \mathrm{N}$ (Fig. 7a). This is a sign of a strengthening of the local meridional circulation between East Asia and the Philippine Sea. Since the surface mean wind off the west coast of Sumatra is northwesterly during this season, the total wind speed increases in February-March of cold SEIO SST years. This may contribute to the observed cooling of SSTs in the eastern equatorial Indian Ocean essentially through enhanced evaporation and vertical mixing since the seasonal winds (northwesterlies) are downwelling favourable during this season. All these features suggest a stronger East Asian winter monsoon. Interestingly, a strong East Asian winter monsoon is one of the precursors of El Niño events identified by Xu and Chan (2001). Over the South Pacific, a cyclonic circulation and anomalous ascent are found off the eastern coast of Australia, where the South Pacific Convergence Zone (SPCZ) is normally located (Fig. 6a). Finally, it is noteworthy that the wind and SST patterns over the central and eastern equatorial Pacific sectors are not significant during February-March of cold SEIO SST years.

SST patterns during boreal spring of the cold SEIO SST years show a decay of the SST dipole pattern (Fig. 5b). However, SEIO SST anomalies tend to persist and move northeastward. This suggests that positive feedbacks between the atmosphere and ocean may allow a persistence of the SST anomaly in the SEIO area. Meanwhile, there are positive omega anomalies and an anticlockwise surface circulation over the SEIO, and negative omega values and an associated clockwise surface circulation between Madagascar and $100^{\circ} \mathrm{E}$ (Fig. 6b). This pattern is the signature of a delayed westward seasonal movement of the Mascarene high from boreal winter to boreal summer (Terray et al., 2003a). In order to diagnose possible air-sea feedbacks, which may allow the persistence of the cold SEIO SST anomalies during boreal spring, the SLP, latent heat flux and rainfall composites observed in April-May of the cold SEIO SST years are shown in Figure 8. For the latent heat flux composites, positive values indicate heat loss from the ocean (Fig. 8c). First, we observe that a low (high) pressure anomaly develops near the warm (cold) SST anomaly in the southern Indian Ocean by AprilMay (Fig. 8a). This result is consistent with what might be expected from linear quasigeostrophic theory (Gill, 1982). That is, a low (high) pressure anomaly is generated over a warm (cool) SST forcing. Moreover, the SLP and rainfall anomaly patterns suggest that the maritime Inter Tropical Convergence Zone (ITCZ) from the North of Madagascar to 
northwestern Australia-Indonesia is weakened while positive precipitation anomalies are observed in the southwest Indian Ocean. These results are consistent with the anomalous divergence (convergence) over SEIO (southwest Indian Ocean) areas in spring of positive SST dipole events (Figs. 6b and 7b). This results in an atmospheric sink over the SEIO. Now, the southeasterly wind anomalies between Sumatra and Australia associated with the anomalous subsidence over the SEIO (Fig. 6b) represent an increase in wind speed relative to climatology, as the seasonal wind changes from northwesterly to southeasterly in this region during boreal spring. This implies further cooling of SEIO SSTs via increased upper ocean mixing and evaporation (Fig. 8c). These cold SST anomalies further decrease atmospheric convection, which reinforces the atmospheric heat sink at higher levels (Fig. 7b). The most suppressed convection and negative rainfall anomalies (Fig. 8e) are located eastward of the anomalous anticyclone (Fig. 8a), suggesting that this anomalous anticyclone is partly an atmospheric response to the heat sink through descending Rossby waves to its west (Gill, 1980). This strengthens the anomalous low-level anticyclonic circulation. These processes represent a seasonally positive feedback between the wind, evaporation and SST in the SEIO (Li et al., 2003; Fischer et al. 2003). It may explain both the persistence and the northeastward shift of the cold SST anomalies there. Furthermore, Fischer et al. (2003) found, using a coupled General Circulation Model (GCM), that this positive feedback is particularly active during boreal winter and spring in the SEIO. On the other hand, the cyclonic wind anomalies over the southwestern Indian Ocean imply Ekman divergence and upwelling. These processes add to the reduced solar radiation and enhanced evaporation off the adjacent warm anomaly (associated with its positive rainfall and anomalous ascendance) to reduce the warm SST anomalies southeast of Madagascar. These processes represent a negative feedback, which may damp the warm SST anomalies in the southwest Indian Ocean (Behera and Yamagata, 2001).

By April-May, the cold SST anomalies have also spread eastward between Australia and the Maritime Continent, reaching the vicinity of New Zealand (Fig. 5b). Associated with these anomalous SSTs, positive omega anomalies also develop over eastern Australia, indicative of anomalous subsidence (Fig. 6b). Prominent southerly wind anomalies and negative rainfall anomalies prevail off the east coast of Australia (Figs. 6b and 8e). This suggests an enhancement and a northward shift of the Australian high in late boreal spring associated with an earlier onset of the Australian winter monsoon. Such a feature has already been noted by $\mathrm{Xu}$ and Chan (2001) as a key factor in determining the onset of El Niño events. In the equatorial western Pacific, significant $850 \mathrm{hPa}$ westerly wind anomalies of about $1.5 \mathrm{~m} / \mathrm{s}$ 
extend now from $130^{\circ} \mathrm{E}$ to the date line (Fig. 6b) and significant easterly $200 \mathrm{hPa}$ wind anomalies also extend eastward (Fig. 7b). This suggests that the meridional flow pattern off Australia produces a strong convergence over the western Pacific, enhancing the westerly anomalies. Finally, significant warm SST anomalies develop south of Australia and off the west coast of Chile, in association with an equatorward shift of the mid-latitude westerlies and an expanded trough in the South Pacific (Figs. 6b and 8a). These changes in the South Pacific extratropical circulation may be viewed in terms of the modulations of the western Pacific regional Hadley cell observed during cold SEIO years (Figs. 6b and 7b). Moreover, the anomalous SLP pattern in Fig. 8a represents a weakening of the SLP gradient around the South Pacific subtropical high which is consistent with a reduction of the trade winds in the south Pacific (Fig. 6b). Van Loon et al. (2003) show the importance of this expanded trough in the South Pacific for the El Niño evolution. Finally, the anomalous SLP and wind patterns at this time of the year highlight possible links between this expanded trough and a modulation of the semiannual oscillation in the South Pacific (Van Loon et al., 2003). These aspects of the SEIO SLP and wind composites need further investigations which will be reported in a future study.

In June-July, anomalous cold SSTs first seen in a large part of the Indian Ocean are now limited to the eastern Indian Ocean (Fig. 5c). This area is similar to the Sumatra area defined by Xie et al. (2002); SSTs in this area have been proven in this study to be an important trigger (with ENSO influence) of TIOD events. At the same time, warm anomalies in the southwest Indian Ocean have considerably weakened. This is consistent with the negative feedback discussed above. However, negative omega anomalies (anomalous ascent) in the central Indian Ocean between $15^{\circ} \mathrm{S}$ and $40^{\circ} \mathrm{S}$ and positive omega anomalies to the west of the cold SSTs in the eastern Indian are persistent features of the atmospheric circulation over the southern Indian Ocean and remain observable at higher levels (Figs 6c and 7c). The associated clockwise circulation in the western Indian Ocean (south of the Equator) suggests a persistent weakening of the Mascarene high during the early ISM of the cold SEIO SST years. Turning our attention now back to the SEIO, the development of significant southeasterly wind anomalies off Sumatra, collocated with the cold SSTs, are again consistent with the persistence of positive feedbacks between the anomalous anticyclone there and the cold SST anomalies to the east ( $\mathrm{Li}$ et al., 2003, Fischer et al., 2003). In addition, a wind-thermoclineSST feedback may now reinforce the cold SST anomalies in the eastern Indian Ocean. That is, the mean surface flow changes from northwesterly downwelling-favourable winds to 
southeasterly upwelling favourable winds along the Sumatra coast in early boreal summer (Fischer et al., 2003). Thus, the low-level anticyclonic anomalous flow southwest of Sumatra in June-July of the cold SEIO SST years accelerates the seasonal southeasterly winds and increases the total wind speed. These anticyclonic surface wind anomalies have an upwelling component along the Sumatra coast and an anomalous easterly component along the equatorial wave guide (Fig. 6c). These factors may contribute to the persistence of the cold SST anomalies off Sumatra as well as the propagation of these anomalies across the equatorial eastern Indian Ocean through upwelling (Fig. 5c). Again, these cold SST anomalies reduce atmospheric convection and rainfall as suggested by the positive omega anomalies (anomalous subsidence) at both 500 and $300 \mathrm{hPa}$ between Australia and Sumatra in Figures $6 \mathrm{c}$ and $7 \mathrm{c}$. This further enhances the mean southeasterly flow off Sumatra that, in turn, reinforces the underlying cold SSTs. According to the coupled GCM results of Fischer et al. (2003), the wind-thermocline-SST feedback is more important than the wind-evaporationSST feedback off the west coast of Sumatra during boreal summer.

In June-July, cold SST anomalies also spread westward into the Pacific Ocean warm pool and southeastward in the south Pacific (Fig. 5c). At the same time, we observe the emergence of significant warm SST anomalies in the central equatorial Pacific. These are connected to the enhanced and persistent warm SST anomalies in the southeast Pacific. Highly significant warm SST anomalies are also found southeast of New Zealand. This Pacific SST anomaly pattern displays evident El Niño features with development of warm SST anomalies in the eastern Pacific and formation of the south branch of the traditional cold horseshoe pattern in the western Pacific (Harrison and Larkin, 1998). In agreement with these SST anomalies, the anomalous wind and omega patterns show anomalous ascent over the central Pacific and a significant weakening of the east-west circulation over the western Pacific (Figs. 6c and 7c). Anomalous subsidence is now found over the Maritime Continent, dynamically consistent with the easterly wind anomalies over the eastern equatorial Indian Ocean and the westerly anomalies over the western Pacific (Fig. 6c). The suppressed convection over the Maritime continent may also reinforce the anomalous SEIO anticyclone via descending Rossby waves to the southwest of this atmospheric heat sink (Wang et al., 2003). The anomalous flow pattern off Australia is similar to April-May with prominent southeasterlies stretching from New Zealand to the Maritime Continent. This may contribute toward the development and eastward propagation of the westerly wind anomalies over the equatorial Pacific.

In August-September, there are positive omega values (anomalous subsidence) over the Indian subcontinent suggesting a weak Late ISM. The SLP composites (not shown) show a 
tilted band of high SLP anomalies stretching from northwestern Australia to the North Arabian Sea. The more significant SLP anomalies are located to the southwest of Sumatra, consistent with the positive feedbacks discussed above. The anomalous circulation pattern suggests a significant weakening of the low-level circulation, as indicated by a reduced Somali Jet and the significant clockwise circulation anomalies apparent around Madagascar (Fig. 6d). At $200 \mathrm{hPa}$, we also observe that both the Tibetan Plateau and Mascarene highs are weakened and shifted eastward during cold SEIO SST years (Fig. 7d). In other words, the whole late ISM circulation is anomalously reduced during cold SEIO SST years. The weaker surface monsoon circulation will influence the Indian Ocean SST variability since wind anomalies are observed in regions where major upwelling occurs (Xie et al., 2002). In the western Indian Ocean, the reduced monsoon flow is accompanied by weaker wind mixing, less evaporation, but also decreasing upwelling along the east Africa coast and south of the Equator (Xie et al., 2002; Webster et al., 2002; Loschnigg et al., 2003). Meanwhile, the weaker ISM induces a stronger interhemispheric gradient in the eastern Indian Ocean with a stronger interhemispheric flow into the Bay of Bengal (Terray et al., 2003a). Even though these wind anomalies are not significant in our composites (Fig. 6d), they do exist (not shown). Thus, the persistent offshore flow near Sumatra will enhance equatorial and coastal upwelling. It may contribute to the northwestward propagation and the amplification of the cold SST anomalies in the eastern Indian Ocean from June-July to August-September (Fig. $5 d)$. In summary, the anomalously weak monsoon winds observed during the late ISM of the cold SEIO SST years will favour warmer water in the western Indian Ocean and colder water in the eastern Indian Ocean. The induced perturbation of the SST gradient across the equatorial Indian Ocean adds to the cold SEIO SSTs, and may then trigger a TIOD event in the following fall (Figs. 5e and 6e) as suggested by Webster et al. (2002).

Significant positive (downward) omega anomalies over the Maritime Continent and negative (upward) omega anomalies in the central Pacific near the date line are observed by August-September (Fig. 6d). The anomalous atmospheric pattern off Australia, characterized by strong southerly wind anomalies, persists. Furthermore, strong northerly wind anomalies now prevail over the Philippine Sea in association with the growth of the west Pacific anomalous anticyclone (Wang et al., 2003). Thus, these two anomalous meridional circulations produce a stronger anomalous convergence over the western equatorial Pacific, which enhances both the westerly anomalies and their eastward propagation over the equatorial Pacific (Fig. 6d). Consistent with this scenario, the 850 and $200 \mathrm{hPa}$ Pacific wind anomaly patterns show the dramatic perturbation of the Walker circulation associated with El 
Niño events. This suggests the SEIO area in boreal winter, as a key precursor of the ENSO evolution in the Pacific, since all these features emerge progressively during cold SEIO SST years.

In October-November, the SST composite depicts the appearance of a TIOD event with an anomalous SST gradient and strong easterly wind anomalies across the equatorial Indian Ocean (Figs. 5e and 6e). This pattern resembles the canonical TIOD event described in Saji and Yamagata (2003, their Fig. 2). Cold SST anomalies are observed south of the equator trapped to the west coast of Indonesia, and a tilted band of positive SST anomalies are seen stretching from the North Arabian Sea to the SEIO. Interestingly, the warm SST anomalies in the western equatorial Indian Ocean are not significant, and the most significant warm SST anomalies are located north and south of the equator. This anomalous SST pattern in the Indian Ocean seems related to the changes in the Late ISM wind pattern described above, still present over the southwestern part of the basin in October-November of the cold SEIO SST years (Fig. 6e). Thus, the anomalous SST pattern caused by the anomalous Late ISM flow seems to trigger the coupled ocean-atmosphere instabilities governing the evolution of a TIOD event (Webster et al., 1999). However, it is noteworthy that this canonical TIOD evolution occurs in association with cold SEIO SST anomalies six months before. This confirms earlier work by Drosdowsky (1993), which showed that SEIO SSTs in late boreal winter is a good precursor of TIOD events. Over the Pacific Ocean, the El Niño pattern is now fully developed with a weakened Walker cell (Figs. 6e and 7e). The eastward propagation of the equatorial westerly wind anomalies continues, now reaching $100^{\circ} \mathrm{W}$. The whole central and eastern equatorial Pacific Ocean is now covered by significant positive rainfall anomalies (not shown), dynamically consistent with the negative omega anomalies observed in these areas (Fig. 6e). The anomalous flow pattern off the east coast of Australia fades away.

In December-January of the following year, the strong signature of the TIOD event evident in October-November dies away (Fig. 5f). The easterly surface wind anomalies along the equatorial Indian Ocean propagate eastward in association with the southeastward seasonal migration of the convective maximum in Indo-Pacific areas (Fig. 6f; Meehl et al., 2003). This evolution is mainly due to the fact that the above-described positive feedbacks switch their sign after boreal fall. After November, the background flows reverse direction over the eastern Indian Ocean. Thus, both the wind-evaporation-SST and wind-thermocline-SST 
feedbacks switch their polarity when the winter monsoon prevails. Anomalously cold SSTs are found south of Madagascar, whereas warm SST anomalies now cover the whole tropical Indian Ocean (Fig. 5f). The anomaly SST pattern observed over the Indian Ocean in December-January is very similar to the one noted in February-March, but with opposite sign and weaker amplitude. This indicates the strong TBO tendency of SEIO SST variability (Fig. 4). The $850 \mathrm{hPa}$ anomalous wind pattern in the southern Indian Ocean is also reversed compared to February-March, and is dynamically consistent with a weaker Mascarene high in austral summer (Fig. 6f). The associated northwesterly wind anomalies off the west coast of Australia may contribute to the reinforcement of the reversed SST dipole pattern for the following year. In the Pacific, the El Niño pattern has now evolved to its mature phase (Fig. 5f). The whole equatorial Pacific is now covered with westerly surface wind anomalies (Fig. 6f). Finally, a remarkable teleconnection Pacific-North American pattern emanating from the central Pacific crosses the North Pacific and extends to North America in the form of a pronounced wave train pattern at both 850 and $200 \mathrm{hPa}$ levels. This result is not a surprise, as the El Niño related SST anomalous pattern in Figure $5 \mathrm{f}$ is known to excite the Pacific-North American pattern during boreal winter (Wallace and Gutzler, 1981). However, the fact that this pattern shows up in SEIO SST composites stresses again the significance of SEIO SST anomalies in the phase transitions of the monsoon-ENSO system.

\section{b. Warm SEIO SST years}

It is of interest that the response of the monsoon-ENSO system to warm SEIO SST anomalies in February-March is of opposite sign although of smaller amplitude during the following 1-yr period (Figs. 9 and 10). By February-March, we observe the occurrence of a negative dipole event in the southern Indian Ocean and a weakening of the East Asian winter monsoon associated with the west Pacific anomalous anticyclone (Wang et al., 2003). From April-May to August-September, significant northerlies persist off the east coast of Australia. During boreal summer, the Maritime Continent and the eastern Indian Ocean are regions of enhanced convection. The SST and atmospheric composites show a La Niña evolution with the emergence of cold SST anomalies in the central equatorial Pacific and easterly surface wind anomalies over the western Pacific and Maritime Continent in June-July (Figs. 9 and 10). The traditional horseshoe pattern also emerges progressively. The Late ISM is stronger than normal during warm SEIO SST years, with a significant enhancement of the interhemispheric ISM circulation from August-September to October-November (Figs. 10de), 
inducing cold SST anomalies in the western Indian Ocean through enhanced evaporation, ocean mixing and upwelling (Fig. 9d). This contributes to the establishment of a negative TIOD event with warm SST anomalies in eastern Equatorial Indian Ocean and cold ones in the west during boreal fall (Fig. 9e). While TIOD variability is evident in warm SEIO SST composites, it has a much lesser significance than in cold composites, with SST anomalies over the equatorial Indian Ocean not significant at the $10 \%$ confidence level in OctoberNovember of the warm SEIO SST years (Fig. 9e).

Thus, similar patterns with reversed polarity are observable, but of course some discrepancies exist. The most striking one occurs in February-March when warm SST anomalies spread over the whole north Indian Ocean and the China Sea (Fig. 9a). A close inspection of the SST, wind and omega composites in February-March of the warm SEIO SST years shows the signature of a negative dipole event in the southern Indian Ocean as might be expected, but also the decay phase of an El Niño event in the Pacific (Figs. 9a and 10a). This is illustrated by significant warm SSTs in the eastern equatorial Pacific and westerly wind anomalies south of the equator in the central Pacific during February-March. Moreover, the association of warm SSTs in the Pacific with warm SSTs in the tropical Indian Ocean during boreal winter (Fig. 9a) has been well documented in the context of El Niño events. This may contribute to the much larger extent of significant warm anomalies observed over the Indian Ocean during February-March of warm SEIO SST years relative to cold ones in cold SEIO SST years (Fig. 5a). However, this feature is not evident by studying selected years for El Niño and warm SEIO SST events (Table 1): only two El Niño years, 1982 and 1997, are followed by warm SEIO SST years (1983 and 1998). Moreover, two La Niña years (1984 and 1995) are also followed by warm SEIO SST years (1985 and 1996). In other words, the greater spatial extent of the warm SST anomalies are certainly attributable to the exceptional strength of both the 1982 and 1997 El Niño events, but negative SST dipole events in the southern Indian Ocean are not necessarily preceded by an El Niño year. This suggests that others factors than ENSO may be responsible for the occurrence of SST dipole events in the south Indian Ocean during austral summer. In this respect, the possible link between the Mascarene high pulses and the variability of the midlatitude circulation in the southern hemisphere needs further investigation and could be an important contributing factor (Fauchereau et al. 2003).

\section{Correlation analysis}


The SEIO SST anomaly in boreal winter has been identified as a precursor to El Niño or the TIOD, with a lead of several months. In this section, we assess its predictive skill through a correlation analysis. We also compare the results with other well-known ENSO precursors.

In accordance with theoretical and observational studies (Jin, 1997; Meinen and McPhaden, 2000), the upper ocean equatorial heat content in the Pacific is a useful ENSO precursor which successfully predicts through the ENSO spring persistence barrier (Clarke and Van Gorder, 2003). This useful property may be explained by the fact that the upper ocean equatorial heat content takes into account the interannual state of the Pacific Ocean (Wyrtki, 1985; Meinen and McPhaden, 2000). As noted in SEIO SST composites, the zonal wind stress anomaly in the far-western equatorial Pacific is another crucial parameter in ENSO evolution (Barnett, 1983; Gutzler and Harrison, 1987). This feature is also somewhat discernable in ENSO composites (Clarke and Van Gorder, 2001, 2003; Xu and Chan, 2001; Wang and Zhang, 2002). As for the upper ocean equatorial heat content, the far-western Pacific zonal equatorial wind stress anomaly leads ENSO events by several months and can predict through the ENSO spring persistence barrier. Based on the precursor properties of Niño3.4 SST, upper ocean equatorial heat content and far-western Pacific zonal equatorial wind stress anomalies, Clarke and Van Gorder (2003) constructed a linear regression model to predict Niño3.4 SST for various leads and showed that this simple model performs at least as well as other ENSO prediction models. To put the results of our analysis in perspective, we first compare the lead correlations of SEIO SST anomalies and these various ENSO precursors with Niño3.4 SST for various leads up to 12 months.

Following Clarke and Van Gorder (2003), we define the upper ocean equatorial heat content as the monthly mean $20^{\circ} \mathrm{C}$ thermocline depth anomaly (Z20 hereafter) averaged over the equatorial Pacific $\left(5^{\circ} \mathrm{S}-5^{\circ} \mathrm{N}, 130^{\circ} \mathrm{E}-80^{\circ} \mathrm{W}\right)$. This time series is computed from the SODA dataset. We define the western equatorial Pacific zonal wind anomaly (WPAC hereafter) to be the zonal $850 \mathrm{hPa}$ wind anomaly area-average over the region $130-160^{\circ} \mathrm{E}, 5^{\circ} \mathrm{S}-5^{\circ} \mathrm{N}$ as suggested by Clarke and Van Gorder (2001, 2003). Figure 11 shows the lag-correlations between Niño3.4 and SEIO in each month and Niño3.4, SEIO, Z20 and WPAC in the preceding winter (February-March). We obtain similar results with other SST indices such as Niño3 or Niño4 or if we define WPAC and Z20 from ENSO composites (not shown). In order to facilitate the comparison between the various ENSO precursors, we also plotted the 95\% confidence levels assuming 25 degrees of freedom and the opposite values of the correlations between SEIO and Niño3.4 in Figure 11. As an illustration, we have a correlation of +0.45 
between SEIO in February-March and Niño3.4 in January, but this correlation is indicated as -0.45 in Figure 11. We first observe that the auto-correlation of Niño3.4 SSTs dies away in July and is near zero after September. This sharp decrease in persistence in the boreal spring of ENSO indices is a result of the phase locking of ENSO to the annual cycle, which tends to cause transitions in ENSO indices to occur during boreal spring (Webster and Yang, 1992; Torrence and Webster, 1998). On the other hand, SEIO persistence remains significantly high until October. This is linked to the fact that these SST anomalies strongly depend on the seasonal evolution of the wind field over the Indian Ocean as described in the previous section. The transition for SEIO SST anomalies occurs in late fall or early boreal winter when the seasonal wind over the eastern Indian Ocean turns from southeasterly to northwesterly. After this reversal of the mean wind, the local air-sea feedbacks in the SEIO change from positive to negative. The easterly wind anomalies do not accelerate but rather decelerate the seasonal wind, which becomes downwelling-favourable along the west coast of Sumatra. This may explain why SEIO auto-correlations decrease rapidly and even change sign from October to December.

Turning now our attention to the prediction of Niño3.4 evolution, we observe that the various ENSO precursors have different relationships with the Niño3.4 monthly time series. Consistent with past studies, the lag-correlation analysis shows that both WPAC and Z20 are significantly related to the occurrence of an El Niño event. WPAC in February-March is positively correlated with Niño3.4 from January to December and the correlation coefficients increase from 0.32 in April to 0.63 in December. The correlations between Z20 and Niño3.4 switch sign in April, then increase rapidly from April to July and slowly from July to December. The highest correlation between Z20 and Niño3.4 is observed in December and is as high as 0.70. Finally, we observe that the correlations between February-March SEIO and monthly Niño3.4 are positive and significant until March, reverse abruptly their sign from April to June as for Z20 and decrease steadily from July to October. From October to December, the correlations between SEIO and Niño3.4 are around -0.70 and -0.75. Moreover, from August to December, the SEIO index gives consistently better results than WPAC or Z20. This period basically concerns the growth and peak of El Niño events (Larkin and Harrison, 2002), thus confirming the significance of SEIO SST anomalies as a precursor to ENSO events. Moreover, the fact that the correlations between SEIO and Niño3.4 evolve from positive and significant in late boreal winter to negative and highly significant in the next boreal winter reinforces the suggestion that Indian Ocean SST anomalies, and 
particularly SEIO ones, play a primordial role in the ENSO transitions during recent decades (Yu et al., 2003).

To further compare the predictive skill associated with SEIO SST anomalies and other ENSO precursors, the lag-correlations between Z20, WPAC, and SEIO in each month and Niño3.4 in October-December are shown in Figure 12. We also present in this figure the correlations with a meridional $850 \mathrm{hPa}$ wind time series off the East coast of AUStralia (EAUS hereafter). Inclusion of this wind index is motivated by the results presented in Section 4 and the work of $\mathrm{Xu}$ and Chan (2001). This time series is defined as the areaaveraged meridional $850 \mathrm{hPa}$ wind anomaly over the region $150-175^{\circ} \mathrm{E}, 15-40^{\circ} \mathrm{S}$ from ENSO composites (not shown). As in Figure 11, opposite values of correlation between SEIO and Niño3.4 are plotted in Figure 12. Figure 12 suggests that SEIO SST anomalies perform at least as well as other well-established ENSO predictors before boreal spring. Correlation between SEIO SSTs in February and Niño3.4 in October-December is as high as -0.74, and SEIO performs better than other predictors for this time lead. This highlights the importance of SST dipole events, highly phase locked with the seasonal cycle, for the emergence of SEIO SST anomalies. Interestingly, significant correlations between WPAC and Niño3.4 occur abruptly in March-April, which is about one to two months after the emergence of SEIO SST anomalies, while the correlations with Z20 remain stable around these months. During boreal summer and fall, WPAC outperforms other indices with maximum correlations around 0.82 in August-September. This suggests that a persistent wind forcing or a collection of anomalous wind forcing events over the far western equatorial Pacific from boreal spring to late boreal summer associated with the eastward shift of the Pacific Walker cell is an important contributory factor in ENSO evolution.

Since the importance of the various ENSO predictors varies with season and SEIO SSTs are among the best ones before boreal spring, it is interesting to investigate relationships between SEIO SSTs in February-March and other ENSO precursors. However, we restrict this analysis to monthly WPAC time series, as the ocean heat content in the equatorial Pacific is an intrinsic quantity of the ENSO process and is not directly related to SEIO SST anomalies, as suggested above. The lag-correlations of SEIO and WPAC (at both 850 and 200 $\mathrm{hPa}$ ) in February-March with monthly 850 and $200 \mathrm{hPa}$ WPAC time series are shown in Figure 13. SEIO in February-March is a better predictor of the evolution of the Pacific Walker cell during summer and fall than the WPAC indices themselves. Interestingly, the correlations with the monthly $200 \mathrm{hPa}$ WPAC index are roughly the opposite of those with the monthly $850 \mathrm{hPa}$ WPAC index from May to December. This suggests that the evolution of the Pacific 
Walker cell has a close relationship with SEIO SST anomalies during late winter. Obviously, SEIO SST anomalies may play an important role in triggering persistent surface wind anomalies over the Pacific warm pool during the growth of El Niño events, via anomalous subsidence over the Maritime Continent, anomalous ascendance over the west Pacific and anomalous southerlies off the northeast coast of Australia associated with the persistent anomalous SEIO anticyclone.

SEIO has also been identified as a possible precursor for TIOD events in boreal fall. In order to confirm this feature, a similar lag-correlation analysis between SEIO SSTs in February-March and various monthly TIOD indices has been undertaken. In addition to SST ETIO, WTIO and TIOD indices defined in Section 3, we also included in this analysis the zonal $850 \mathrm{hPa}$ wind anomaly over the equatorial Indian Ocean $\left(5^{\circ} \mathrm{S}-5^{\circ} \mathrm{N}, 70^{\circ}-90^{\circ} \mathrm{E}\right.$, Ueq hereafter) in order to clearly identify the coupled air-sea TIOD pattern over the tropical Indian Ocean. The results presented in Figure 14 appear to be consistent with those of Sections 3 and 4. For instance, SEIO SSTs in February-March are significantly and positively correlated with ETIO SSTs from January to November. The correlations increase from August to October, suggesting the existence of a positive feedback during these months, and rapidly fade away afterwards. Similarly, correlations with WTIO SSTs are highly positive during boreal winter, but reverse their sign during boreal summer to become significantly negative in November. In other words, these lag-correlations reproduce the phase lag in the SST anomaly evolution between ETIO and WTIO, which characterizes TIOD events (Saji and Yamagata, 2003). Finally, the correlations with TIOD and Ueq indices are highest and significant during October and November, suggesting that SEIO SST anomalies in February-March may trigger the coupled air-sea instability inherent in TIOD events. Together, these results suggest that subtropical Indian Ocean SST anomalies in February-March are also a significant precursor of TIOD indices during fall, the peak season of TIOD events.

SEIO has also been suggested as a significant precursor for the variability of the various monsoon systems in the Indo-Pacific region. Table 2 lists the correlation coefficients of SEIO SSTs in February-March with rainfall and dynamical indices for the Indian and Australian monsoon systems during the following boreal summer, fall and winter. In addition to the AIRI, MCR, and Australian monsoon indices, we have included the ISM dynamical indices proposed by Wang and Fan (1999) and Wang et al. (2001). Based on empirical relationships between convection and vertical shear anomalies, they proposed that the ISM system may be represented by a Westerly Shear Index (WSI1), a Southerly Shear Index (SSI1) and the 
difference of the zonal wind anomalies (DU1) between a southern region and a northern region. The precise definition of these indices is given in the caption of Table 2 .

For the Early ISM (June-July), the correlations of the rainfall and dynamical ISM indices with SEIO SSTs in February-March are all negligibly small. However, these correlation coefficients become positive and significant at least at the $99 \%$ confidence level for the Late ISM. This corroborates the fact that SEIO SST variability is essentially linked to the Late ISM even though this feature is not well understood (Terray et al., 2003a). Interestingly, the highest correlation is observed for SSI1 (0.66), which is related to the cross-equatorial flow off the African coast and the local Hadley circulation. This is consistent with the existence of positive air-sea feedbacks in the SEIO during late summer (Terray et al., 2003a). It is interesting to observe that warm SEIO SST anomalies in February-March are followed by positive and significant rainfall anomalies over the Maritime Continent and North Australia from early summer to winter (Table 2). Once again, the coefficients are particularly high during August-September. This implies that SEIO SSTs are linked to both the winter and summer Australian monsoons in addition to the Maritime Continent heat source. This is in agreement with the composite analysis of Section 4.

\section{Summary and discussion}

Because the SST signal in the Pacific Ocean precedes that in the Indian Ocean during boreal fall and winter, the possibility that the Indian Ocean plays a role in ENSO evolution has been largely overlooked in the past. Since the late 1970s, the evolution of ENSO events and the relationships between the ISM and ENSO have significantly changed. The purpose, therefore, of this paper is to statistically re-examine, the relationship between Indian Ocean SSTs and the whole monsoon-ENSO system, noting especially the changes that have taken place after 1976.

a. Observational results

Composite analyses of SST fields with respect to ENSO, (Late) ISM, AUSM, MCR, and TIOD indices reveal that southern Indian Ocean SST dipole events during boreal winter are the unique common SST precursor of these various phenomena before the growth of ENSO events in boreal spring. SEIO SST anomalies induced by such dipole events are highly persistent. This reinforces the idea that Indian Ocean SST anomalies, and particularly those in 
the SEIO, play a primordial role in the transitions of the monsoon-ENSO system (Yu et al., 2003). Wavelet analysis of a SEIO SST index reveals that SEIO SST anomalies are intimately linked to the TBO both before and after the 1976-1977 regime shift. To reveal differences between cold and warm SEIO SST years, SST, wind, omega, SLP, latent heat flux and rainfall anomalies over the Indo-Pacific basin were composited for each type of year from FebruaryMarch to December-January. These composite analyses suggest that SEIO SST anomalies have a strong and significant association with the evolution of the whole Indo-Pacific system during the following 1-yr period. Anomalously cold (warm) SEIO SSTs form in FebruaryMarch due to a strengthening of the Mascarene high and associated surface wind forcing off the west coast of Australia. SEIO SST anomalies persist and slowly propagate in the tropical eastern Indian Ocean through the subsequent spring, summer and fall, providing a prolonged impact on the whole monsoon-ENSO or TBO system. Cold (warm) SEIO SSTs in late boreal winter are followed by a stronger (weaker) Australian winter monsoon, reduced (enhanced) rainfall over the Maritime Continent during boreal summer, a weak (strong) Late ISM, a positive (negative) TIOD event in the tropical Indian Ocean and an El Niño (La Niña) evolution in the Pacific from boreal spring to the next boreal winter. The most important features in this composite analysis with respect to the transitions of the whole monsoonENSO system are the development of the SEIO anomalous anticyclone (cyclone) from AprilMay to October-November associated with cold (warm) SEIO SST anomalies, persistent southerlies (northerlies) which prevail from April-May to August-September off the east coast of Australia and wind anomalies over the western equatorial Pacific through boreal spring and summer. These three key factors are intricately linked through various seasonally positive ocean-atmosphere feedbacks. To some extent, the above features are consistent with previous studies on precursors of El Niño events or transitions of the whole monsoon-ENSO system (Van Loon and Shea, 1985; Wang, 1995; Xu and Chan, 2001; Wang et al., 2003; Meehl et al., 2003). A correlation analysis supports these results and suggests again that SEIO SST anomalies exert a strong influence on the transitions of the whole monsoon-ENSO system. As an illustration, the anomalous equatorial Pacific upper ocean heat content and the equatorial wind anomalies in the western Pacific are two excellent ENSO predictors that can predict across the boreal spring (Clarke and Van Gorder, 2001, 2003). SEIO SST anomalies during February-March lead the SST Niño3.4 index with a correlation of 0.75 or more for November-December of the same year. Thus, the SEIO SST index can predict ENSO indices across the spring persistence barrier like the above predictors. Moreover, it has higher predictive skill than these two fundamental predictors after the 1976-1977 regime shift. 
Significant and high correlations are also obtained for TIOD, Late ISM, AUSM, MCR indices with a considerable time lead across the spring predictability barrier. This demonstrates that SEIO SST variability during boreal winter is related in some fundamental manner to the transitions of the whole monsoon-ENSO system even though the various components of this system are not always synchronized.

\section{b. Discussion}

Two different seasonally positive feedbacks between the atmosphere and the ocean may explain the extraordinary persistence of SEIO SST anomalies from late boreal winter until boreal fall. The first one is a seasonally positive feedback between wind, evaporation and SST in the SEIO. In agreement with linear quasi-geostrophic theory, a high (low) pressure anomaly is generated near the cold (warm) SEIO SST anomalies induced by the occurrence of a positive (negative) subtropical SST dipole event. During boreal spring, the seasonal wind reverses sign from northwesterly to southeasterly between Sumatra and Australia. Thus, the anomalous anticyclonic flow associated with the high pressure anomaly adds to the total wind speed during boreal spring over the SEIO, implying further cooling of the underlying SSTs via increased upper ocean mixing and evaporation. It is well-known that the atmosphere response to a cold or a warm SST anomaly is much more pronounced when the underlying SST climatology is closer to $27^{\circ} \mathrm{C}$, above which the nonlinear relationship between convection and SST becomes pronounced (Gill, 1982). This is exactly the case in the SEIO during boreal spring. Furthermore, the SEIO is a region of active convection during boreal spring. These factors contribute to reduce rainfall and convection over the SEIO, implying an atmospheric heat sink at higher levels, which may generate descending Rossby waves to the west, enhancing the initial high pressure anomaly. The observed seasonal cycle along the Sumatra coast shows a reversal from downwelling-favourable to upwelling-favourable winds during early boreal summer. A wind-thermocline-SST feedback may then reinforce the lack of convection and the cold SST anomalies along the Sumatra coast and in the eastern equatorial Indian Ocean. This may contribute to the fact that the anomalous SEIO anticyclone reaches its peak intensity in late summer and fall. The wind-thermocline/evaporation-SST feedbacks are the positive feedback mechanisms proposed by Wang et al. (2003) to explain the extraordinary amplification during boreal summer and the subsequent fall peak of the SEIO anticyclone, and are among the positive feedbacks involved in the growth of TIOD events following Li et al. (2003). However, it is remarkable that the growth of the SEIO 
anticyclone may be traced back to SEIO SST anomalies, which first appear during boreal winter. The emergence of this anomalous surface circulation over the southern Indian Ocean in cold SEIO SST composites is an important finding of the present study since it implies that cold SEIO SSTs in February-March are a significant precursor of this large anomalous circulation.

The results of this study verify the findings of Terray et al. (2003a) regarding the significant relationships between SEIO SST anomalies and Late ISM variability for the two recent decades. Persistent SEIO SST anomalies affect the seasonal translation of the Mascarene high during boreal spring and early summer, inducing a weaker southern subtropical anticyclone, a weakened interhemispheric monsoon circulation over the western Indian Ocean, and negative rainfall anomalies over the Indian subcontinent during the Late ISM of recent decades. The Late ISM-related wind anomalies occur in regions where major upwellings take place in the Indian Ocean (Xie et al., 2002; Webster et al., 2002). A reduced Somali jet is accompanied by weaker wind mixing, evaporation and upwelling, leading to warmer SSTs in the western Indian Ocean during late summer. At the same time, the enhanced onshore flow towards Sumatra favours cooler SSTs in the eastern Indian Ocean via coastal and equatorial upwellings. Meanwhile, anomalous subsidence rapidly intensifies over the Maritime Continent, further reinforcing the anomalous SEIO anticyclone via descending Rossby waves to the southwest of the heat sink in the upper atmosphere. Turning our attention now to TIOD variability in boreal fall, the east-west SST gradient caused by the anomalous Late ISM may then force zonal wind anomalies over the equatorial Indian Ocean. The strong easterly wind anomalies following a weak Late ISM could produce a weakening of the Wyrtki jet in October-November which will reduce the build-up of warm water to the east (Vinayachandran et al., 1999). Additionally, the dynamic ocean response to these wind anomalies is to deepen the thermocline in the western Indian Ocean via downwelling Rossby waves (Webster et al., 1999). The anomalous warming in the southwestern tropical Indian Ocean away from the equator observed during boreal fall of cold SEIO SST years (Fig. 5e) may be due to a locally-forced deepened thermocline induced by such westward-propagating Rossby waves (Xie et al., 2002). In other words, the anomalous Late ISM circulation may trigger the coupled ocean-atmosphere instabilities associated with TIOD events (Webster et al., 1999). However, the relationship between ISM and TIOD events remains controversial and needs further investigation. One suggestion is that positive TIOD events enhance ISM rainfall (Ashok et al., 2001; Li et al., 2003), although Li et al. (2003) argue that the strong 
ISM will tend to damp the original TIOD event. Others suggest that positive TIOD events normally coincide with dry conditions over the Indian subcontinent, the two phenomena being integral parts of the TBO system (Webster et al., 2002; Loschnigg et al., 2003; Meehl et al., 2003). Thus, a better understanding of the linkages of ISM rainfall and circulation anomalies with the mechanisms governing TIOD events is clearly needed. One possible reason for these discrepancies is the fundamental differences between the early and late ISM as suggested by Ailikun and Yasunari (2002) or Terray et al. (2003a) and further illustrated in Table 2 where the correlations between the February-March SEIO time series and the dynamical and rainfall ISM indices are near zero in June-July, but positive and highly significant in AugustSeptember.

The ENSO cycle is phase-locked with the annual cycle and an El Niño, for example, develops in boreal spring. In addition to SST and anomalous heat content in the equatorial western Pacific, the local wind anomalies over the western Pacific and Indian Ocean warm pool have also been considered as a key-factor for ENSO transitions (Meinen and McPhaden, 2000; Clarke and Gorder, 2003). This idea was tested in many numerical experiments (Lengaigne et al., 2002). The results confirm the effects of the westerly anomalies on the growth of ENSO events. In the ENSO process, the SST and ocean heat content are two fundamental oceanic quantities, but they are not directly related to SEIO SST variability. On the other hand, one should note that the wind anomalies over the warm pool are largely forced by remote factors such as cold surges, modulation of the convection over the Maritime Continent, or the local meridional circulation in both hemispheres. Our results suggest that there are precursors to ENSO events in the southern Indian Ocean that develop before the boreal spring and the growth of El Niño events. The extraordinary persistence of both the SEIO SST anomalies and anomalous anticyclone provides possible links between southern Indian Ocean variability during boreal winter and low-frequency processes in the Pacific Ocean during the following year. We argue that SEIO SST anomalies have a delayed or prolonged impact on ENSO variability through this anomalous SEIO anticyclone and a modulation of the convection over the Maritime continent and the western Pacific. This anticyclone may act to suppress the convection over the Maritime Continent and induce a collection of westerly wind bursts or persistent westerly wind anomalies over the Pacific Ocean warm pool from boreal spring through fall. Additionally, this anticyclone induces an earlier and stronger Australian winter monsoon in boreal summer. Thus, the anomalous and persistent meridional circulation (southerlies) off the east coast of Australia produce stronger convergence over the western equatorial Pacific, which may further intensify the Pacific 
westerly wind anomalies. It is then possible that these persistent westerly winds located over the equatorial west Pacific may trigger an El Niño event or strengthen an existing one. However, the precise mechanisms (westerly wind bursts in boreal spring, suppressed convection over the Maritime Continent during summer, persistent southerlies off the west coast of Australia from April-May to October-November) and their relative contributions by which the remote SEIO SST anomalies affect the ENSO evolution remain to be clarified with careful coupled GCM experiments. The above scenario is similar to the TBO evolution over 1-yr period described by Meehl et al. (2003), with three important exceptions. Our results point to southern Indian Ocean SSTs, an anomalous SEIO anticyclone, and an associated anomalous meridional cell off the east coast of Australia (indicative of a stronger Australian winter monsoon), as major contributors to the TBO transitions after the 1976-1977 regime shift.

A subsequent study is planned with a full coupled GCM to more comprehensively investigate the details of the response of the monsoon-ENSO system to SST dipole events in the southern Indian Ocean during austral summer. Finally, additional model and observational studies are also needed to document the physical mechanisms which govern the Mascarene high pulses during boreal winter. In this context, the possible links between the different modes of variability of the midlatitude circulation in the southern hemisphere (Simmonds, 2003) and the Mascarene high pulses during boreal winter have thus far received little attention in the research community. As noted by White et al. (2002), teleconnections exist between mid and high latitudes of the southern hemisphere (the Antarctic circumpolar wave) and east tropical Pacific (the global ENSO wave) through ocean and atmosphere pathways during recent decades. These connections need further investigations in the future.

Acknowledgments. This work was supported by the French Programme National d'Etude Du Climat (PNEDC). The NCAR/NCEP reanalysis data was provided through the NOAA Climate Center (http://www.cdc.noaa.gov) and SODA analysis data from the IRI data library server (http://iridl.columbia.edu). Wavelet software was provided by C. Torrence and G. Compo, and is available at URL: http://paos.colorado.edu/research/wavelets/. Computations were performed at the French Institute for Development and Resources in Scientific Computing (IDRIS). Graphics prepared using the SAXO package of Sébastien Masson. We thank A.S. Fischer and G. Reverdin for final comments and careful re-reading of the manuscript. We also thank the anonymous reviewers for their comments that improved this paper. 


\section{Appendix A}

Definition of the acronyms used in the paper. The dynamical indices DU1, SSI1 and WSI1 are defined and discussed in Wang and Fan (1999) and Wang et al. (2001).

\begin{tabular}{|l|l|}
\hline AIRI & All India Rainfall Index \\
\hline AUSM & AUstralian Summer Monsoon \\
\hline CMAP & Climate prediction center Merged Analysis of Precipitation \\
\hline DU1 & Difference of the zonal wind anomalies \\
\hline EAUS & East coast of AUStralia \\
\hline ENSO & El Niño - Southern Oscillation \\
\hline ERSST & Extended Reconstruction of global SST \\
\hline ETIO & Eastern Tropical Indian Ocean \\
\hline GCM & General Circulation Model \\
\hline ISM & Indian Summer Monsoon \\
\hline ITCZ & Inter Tropical Convergence Zone \\
\hline MCR & Maritime Continent Rainfall \\
\hline SEIO & South East Indian Ocean \\
\hline SLP & Sea Level Pressure \\
\hline SODA & Simple Ocean Data Assimilation \\
\hline SPCZ & South Pacific Convergence Zone \\
\hline SSI1 & Southerly Shear Index \\
\hline SST & Sea Surface Temperature \\
\hline TBO & Tropospheric Biennial Oscillation \\
\hline TIOD & Tropical Indian Ocean Dipole \\
\hline WPAC & Western equatorial PACific zonal wind anomaly \\
\hline WSI1 & Westerly Shear Index \\
\hline WTIO & Western Tropical Indian Ocean \\
\hline Z20 & Monthly mean 20 ${ }^{\circ}$ thermocline depth anomaly \\
\hline
\end{tabular}




\section{REFERENCES}

Ailikun, B., and T. Yasunari, 2001: ENSO and Asian Summer Monsoon : Persistence and Transitivity in the Seasonal March. J. Meteor. Soc. Japan, 79, 145-159.

Allan, R.J. and coauthors, 2001: Is there an Indian Ocean dipole, and is it independent of the El Nino-Southern Oscillation? CLIVAR Exch., 6 (3),18-22.

Alexander M.A., I. Bladé, M. Newman, J.R. Lanzante, N.-C. Lau and J.D Scott, 2002 : The Atmospheric Bridge : the Influence of ENSO Teleconnections on Air-Sea Interaction over the Global Oceans. J. Climate, 15, 2205-2231.

Anderson, D., 1999: Climatology: extremes in the Indian Ocean. Nature, 401, 337-338.

Ashok, K., Z. Guan, and T. Yamagata, 2001: Impact of the Indian Ocean dipole on the relationship between the Indian monsoon rainfall and ENSO. Geophys. Res. Lett., 28, 44994502.

Ashok, K., Z. Guan, and T. Yamagata, 2003: A look at the relationship between the ENSO and the Indian Ocean dipole. J. Meteor. Soc. Japan, 81, 41-56.

Ashok, K., Z. Guan, and T. Yamagata, 2003: Influence of the Indian Ocean Dipole on the Australian winter rainfall. Geophys. Res. Lett., 30, 61-64.

Baquero-Bernal, A., and M. Latif, 2002: On dipole-like variability in the tropical Indian Ocean. J. Climate, 15, 1358-1368.

Barnett, T.P., 1983: Interaction of the monsoon and Pacific trade wind system at interannual time scales. Part I: The equatorial zone. Mon. Wea. Rev., 111, 756-773.

Behera S. K., and T. Yamagata, 2001: Subtropical SST dipole events in the southern Indian Ocean. Geophys. Res. Lett., 28, 327-330.

Behera S. K., and T. Yamagata, 2003: Impact of the Indian Ocean Dipole on the Southern Oscillation. J. Meteor. Soc. Japan, 81, 169-177.

Carton J.A., G. Chepurin, X. Cao and B. Giese, 2000a: A Simple Ocean Data Assimilation Analysis of the Global Upper Ocean 1950-95. Part 1: Methodology. J. Phys. Oceanogr., 30, 294-309.

Carton J.A., G. Chepurin, and X. Cao, 2000b: A Simple Ocean Data Assimilation Analysis of the Global Upper Ocean 1950-95. Part 2: Results. J. Phys. Oceanogr., 30, 311-326.

Chandrasekar, A., and A. Kitoh, 1998: Impact of localized sea surface temperature anomalies over the equatorial Indian Ocean on the Indian summer monsoon. J. Meteor. Soc. Japan, 76, 841-853.

Chang, C.P., and T. Li, 2000: A theory for the tropical tropospheric biennial oscillation. $J$. Atmos. Sci., 57, 2209-2224. 
Clark, C.O., J.E. Cole, and P.J. Webster, 2000: Indian Ocean SST and Indian summer rainfall: Predictive relationships and their decadal variability. J. Climate, 13, 2503-2519.

Clarke A.J. and S. Van Gorder (2001): ENSO prediction using an ENSO trigger and a proxy for western equatorial Pacific warm pool movement. Geophys. Res. Lett., 28(4), 579-582.

Clarke A.J. and S. Van Gorder (2003): Improving El Niño Prediction using a Space-Time Integration of Indo-Pacific Winds and Equatorial Pacific Upper Ocean Heat Content. Geophys. Res. Lett., 30(7), 52.1-52-4.

Drosdowsky W, 1993: Potential Predictability of Winter Rainfall over Southern and Eastern Australia using Indian Ocean Sea-Surface Temperatures Anomalies. Aust. Meteor. Mag., 42, $1-6$.

Drosdowsky, W., and M. Williams, 1991: The Southern Oscillation in the Australian Region. Part I: Anomalies at the extremes of the Oscillation. J. Climate, 4, 619-638.

Drosdowsky W. and L.E. Chambers, 2001: Near-Global Sea Surface Temperature Anomalies as Predictors of Australian Seasonal Rainfall. J. Climate, 14, 1677-1687.

Fauchereau, N., S. Trzaska, Y. Richard, P. Roucou and P. Camberlin, 2003: Sea-Surface Temperature co-variability in the southern Atlantic and Indian oceans and its connections with the atmospheric circulation in the Southern Hemisphere. Int. J. Climatol., 23, 663-677.

Fischer, A.S., P. Terray, P. Delecluse, S. Gualdi and E. Guilyardi, 2003: Triggers for Tropical Indian Ocean Variability and Links to ENSO in a Constrained Coupled Climate Model. In revision for Journal of Climate.

Gershunov, A., and T.P. Barnett, 1998: Interdecadal modulation of ENSO teleconnections. Bull. Amer. Meteor. Soc., 79, 2715-2825.

Gill, A.E., 1980: Some simple solutions for heat-induced tropical circulation. Quart. J. Roy. Meteor. Soc., 106, 447-462.

Gill, A.E., 1982: Atmosphere-Ocean Dynamics. Academic Press, New York, 662 pp.

Goddard, L. and N.E. Graham, 1999: The importance of the Indian Ocean for simulating precipitation anomalies over eastern and southern Africa. J. Geophys. Res., 104: 1909919116.

Gutzler, D.S., and D.E. Harrison, 1987: The structure and evolution of seasonal wind anomalies over the near-equatorial eastern Indian and western Pacific Oceans. Mon. Wea. Rev., 115, 169-172.

Harrison, D.E. and N.K. Larkin, 1998: El Niño-Southern Oscillation Sea Surface Temperature and Wind Anomalies, 1946-1993. Rev. Geophy., 36 (3), 353-399.

Harzallah A. and R. Sadourny, 1997: Observed lead-lag relationships between Indian summer monsoon and some meteorological variables. Clim. Dyn., 13, 635-648. 
Hendon H.H., 2003: Indonesian Rainfall Variability: Impacts of ENSO and Local Air-Sea Interactions. J. Climate, 16, 1775-1790.

Iizuka, S., T. Matsuura, and T. Yamagata, 2000: The Indian Ocean SST dipole simulated in a coupled general circulation model. Geophys. Res. Lett., 27, 3369-3372.

Jin, F.F., 1997: An equatorial ocean recharge paradigm for ENSO. Part I: Conceptual model. J. Atmos. Sci., 54, 811-

Kalnay and co-authors, 1996: The NCEP/NCAR 40-Year Reanalysis Project. Bull. Amer. Meteor. Soc., 77, 437-471.

Kidson, J.W. and J.A. Renwick, 2002: The Southern Evolution of ENSO during 1981-99. J. Climate, 15, 847-863.

Kinter, J.L., K. Miyakoda., and S. Yang, 2002: Recent change in the connection from the Asian Monsoon to ENSO. J. Climate, 15, 1203-1215.

Klein S.A., B.J. Soden and N.-C. Lau, 1999 : Remote sea Surface Temperature Variations during ENSO : Evidence for a Tropical Atmospheric Bridge. J. Climate, 12, 917-932.

Kumar, K.K., B. Rajagopalan, and M.A. Cane, 1999: On the weakening relationship between the Indian monsoon and ENSO. Science, 284, 2156-2159.

Larkin, N.K., and D.E. Harrison, 2002: ENSO Warm (El Niño) and Cold (La Niña) Events Life Cycles: Ocean, Surface Anomaly Patterns, their Symmetries, Asymmetries, and Implications. J. Climate, 15, 1118-1140.

Lau, K.M., and H.-T. Wu, 2001: Principal modes of rainfall-SST variability of the Asian summer monsoon: A re-assessment of monsoon-ENSO relationships. J. Climate, 14, 28802895.

Lau, N.C., and M.J. Nath, 2000: Impact of ENSO on the Variability of the Asian-Australian Monsoons as Simulated in GCM Experiments. J. Climate, 13, 4287-4309.

Lau, N.C., and M.J. Nath, 2003: Atmosphere-Ocean Variations in the Indo-Pacific Sector during ENSO Episodes. J. Climate, 16, 3-20.

Lengaigne, M., J.B. Boulanger, C. Menkes, S. Masson, G. Madec, and P. Delecluse, 2002: Ocean response to the March 1997 Westerly Wind Event. J. Geophys. Res., 107(C12), 8015.

Li, T., C.-W Tham, and C.P. Chang, 2001a: A coupled air-sea-monsoon oscillator for the troposheric biennial oscillation. J. Climate, 14, 752-764.

Li, T., Y.S. Zhang, C.P. Chang, and B. Wang, 2001b: On the relationship between Indian Ocean SST and Asian summer monsoon. Geophys. Res. Lett., 28, 2843-2846.

Li, T., B. Wang, C.P. Chang and Y.S. Zhang, 2003: A theory for the Indian Ocean DipoleZonal Mode. J. Atmos. Sci., 60, 2119-2135. 
Loschnigg, J., G.A. Meehl, J.M. Arblaster, G.P. Compo, and P.J. Webster, 2003: The Asian monsoon, the tropospheric biennial oscillation, and the Indian Ocean dipole in the NCAR CSM. J. Climate, 16, 1617-1642.

Lu R., 2001: Interannual Variability of the Summertime North Pacific Subtropical High and its Relation to Atmospheric Convection over the Warm Pool. J. Meteo. Soc. Jap., 79, 771783.

McBride, J.L., and N. Nicholls, 1983: Seasonal relationships between Australian rainfall and the Southern Oscillation. Mon. Weather Rev., 111, 1998-2004.

McBride J.L., M.R. Haylock and N. Nicholls, 2003: Relationships between the Maritime Continent Heat Source and the El Niño-Southern Oscillation Phenomenon. J. Climate, 16, 2905-2914.

Meehl, G. A., 1987: The annual cycle and interannual variability in the tropical Indian and Pacific Ocean regions. Mon. Wea. Rev., 115, 27-50.

Meehl, G. A., 1997: The South Asian monsoon and the tropospheric biennial oscillation. $J$. Climate, 10, 1921-1943.

Meehl, G.A., and J. Arblaster, 2002a: The tropospheric biennial oscillation and the AsianAustralian monsoon rainfall. J. Climate, 15, 722-744.

Meehl, G.A., and J. Arblaster, 2002b: Indian monsoon GCM sensitivity experiments testing tropospheric biennial oscillation transition conditions. J. Climate, 15, 923-944.

Meehl G.A., J.M. Arblaster and J. Loschnigg, 2003: Coupled Ocean-Atmosphere Dynamical Processes in the Tropical Indian and Pacific Oceans and the TBO. J. Climate, 16, 2138-2158.

Meinen, C.S., and M.J. McPhaden, 2000: Observations of warm water volume changes in the equatorial Pacific and their relationship to El Niño and La Niña. J. Climate, 13, 3551-3559, 2000 .

Nicholls, N., 1989: Sea surface temperatures and Australian winter rainfall. J. Climate, 2., 965-973.

Nitta, T., and S. Yamada, 1989: Recent warming of tropical sea surface temperature and its relationship to the Northern Hemisphere circulation. J. Meteor. Soc. Japan, 67, 375-383.

Parthasarathy B., A.A. Munot and D.R. Kothawale, 1995: All India monthly and seasonal rainfall series: 1871-1993. Theor. and Appl. Climatol., 49, 217-224.

Pierce, D.W., 2002: The role of sea surface temperatures in interactions between ENSO and the North Pacific Oscillation.

Rao, A.S., S.K. Behera, Y. Masumoto, and T. Yamagata, 2002: Interannual variability in the subsurface tropical Indian Ocean. Deep-Sea Res., 49B, 1549-1572. 
Reason, J.C.J., and H.M. Mulenga, 1999: Relationships between South African rainfall and SST anomalies in the southwest Indian Ocean. Int. J. Climatol., 19, 1651-1673.

Reason, J.C.J., 2002: Sensitivity of the southern African circulation to dipole sea-surface temperature patterns in the South Indian Ocean. Int. J. Climatol., 22, 377-393.

Reverdin, G., D.L. Cadet and D. Gutzler, 1986: Interannual displacements of convection and surface circulation over the equatorial Indian Ocean. Quart. J. Roy. Meteor. Soc., 112, 43-67.

Ropelewski, C.F., M.S. Halpert and X. Wang, 1992: Observed tropospheric biennial variability and its relationship to the Southern Oscillation. J. Climate, 5, 594-614.

Saji, N.H., B.N. Goswami, P.N. Vinayachandran and T. Yamagata, 1999: A Dipole Mode in the Tropical Indian Ocean. Nature, 401, 360-363.

Saji, N.H, and T. Yamagata, 2003: Structure of SST and Surface Wind Variability during Indian Ocean Dipole Mode Events: COADS Observations. J. Climate, 16, 2735-2751.

Saji, N.H, and T. Yamagata, 2004: Interference of teleconnection patterns generated from the tropical Indian and Pacific Oceans. Submitted to Climate Research.

Shinoda, T., M.A. Alexander and H.H. Hendon, 2004: Remote response of the Indian Ocean to interannual SST variations in the tropical Pacific. J. Climate, 17, 362-372.

Simmonds, I., 2003: Modes of atmospheric variability over the Southern Ocean. . J. Geophys. Res., 108(C4), 8078.

Smith T.M. and R.W. Reynolds, 2003: Extended Reconstruction of Global Sea Surface Temperatures Based on COADS Data (1854-1997). J. Climate, 16, 1495-1510.

Terray, P., P. Delecluse, S. Labattu and L. Terray, 2003a: Sea Surface Temperature Associations with the Late Indian Summer Monsoon. Clim. Dyn., 21, 593-618.

Terray P., E. Guilyardi, A.S. Fischer and P. Delecluse, 2003b: Dynamics of Indian Monsoon and ENSO Relationships in the SINTEX Coupled Model. Clim. Dyn. in press.

Torrence C., and P. Compo, 1998: A practical guide to Wavelet Analysis. Bull. Amer. Meteor. Soc., 79, 61-78.

Torrence C., and P.J. Webster, 1998: The annual cycle of persistence in the El Niño/Southern Oscillation. Q.J.R. Meteorol. Soc., 124, 1985-2004.

Trenberth, K.E., 1997: The Definition of El Niño. Bull. Amer. Meteor. Soc., 78, 2771-2777.

Van Loon, H., and D.J. Shea, 1985: The southern Oscillation. Part IV: The precursors south of $15^{\circ} \mathrm{S}$ to the extremes of the Oscillation. Mon. Wea. Rev., 113, 2063-2074.

Van Loon, H., G.A. Meehl and R. Milliff, 2003: The Southern Oscillation in the early 1990s. Geophys. Res. Lett., 30, 311-314. 
Vinayachandran, P.N., N.H. Saji and T. Yamagata, 1999: Response of the equatorial Indian Ocean to an unusual wind event during 1994. Geophys. Res. Lett., 26, 1613-1616.

Wallace, J.M., and D.S. Gutzler, 1981: Teleconnections in the geopotential height field during the Northern Hemisphere winter. Mon. Wea. Rev., 109, 784-812.

Wang, B., 1995: Interdecadal changes in El Niño onset in the last four decades. J. Climate, 8, 267-285.

Wang B. and S.-I. An, 2001: Why the Properties of El Niño Changed during the Late 1970s. Geophys. Res. Lett., 28, 3709-3712.

Wang, B., and Z. Fan, 1999: Choice of South Asian summer monsoon indices. Bull. Amer. Meteor. Soc., 80, 629-638.

Wang, B., R. Wu, and K.-M. Lau, 2001: Interannual Variability of the Asian Summer Monsoon: Contrasts between the Indian and the Western North Pacific-East Asian Monsoons. J. Climate, 14, 4073-4090.

Wang B. and Q. Zhang, 2002: Pacific-East Asian teleconnection. Part II: How the Philippine Sea anomalous anticyclone is established during El Niño development. J. Climate, 15, 32523265 .

Wang B., R. Wu and T. Li, 2003: Atmosphere-Warm Ocean Interaction and its Impacts on Asian-Australian Monsoon Variation. J. Climate, 16, 1195-1211.

Webster P. J., and S. Yang, 1992: Monsoon and ENSO: Selectively interactive systems. Q. J. R. Meteorol. Soc., 118, 877-926.

Webster P.J., V.O. Magana, T.N. Palmer, J. Shukla, R.A. Tomas, M. Yanai and T. Yasunari, 1998 : Monsoons: Processes, Predictability and the Prospects for Prediction. J. Geophys. Res., 103 (C7), 14451-14510.

Webster P.J., A.M. Moore, J.P. Loschnigg and R.R. Leben, 1999: Coupled ocean-atmosphere dyniamics in the Indian Ocean during 1997-1998. Nature, 401, 356-360.

Webster, P. J., C. Clark, G. Cherikova, J. Fasullo, W. Han, J. Loschnigg, and K. Sahami, 2002: "The Monsoon as a self-regulating coupled ocean-atmosphere system." Meteorology at the Millennium. Academic Press, 198-219.

White, W.B., and S.-C. Chen, 2002: Positive feedbacks between the Antarctic circumpolar wave and the global El Niño-Southern Oscillation wave. J. Geophys. Res. 107, 29.1-29.17.

Wu, R., and B. Wang, 2002: A contrast of the East Asian Summer Monsoon-ENSO relationship between 1962-1977 and 1978-93. J. Climate, 15, 3266-3279.

Wyrtki, K., 1985: Water displacements in the Pacific and the genesis of El Niño cycles. $J$. Geophys. Res., 90, 7129-7132. 
Xie P. and P.A. Arkin, 1997: Global Precipitation: a 17-year Monthly Analysis Based on Gauge Observations, Satellite Estimates, and Numerical Outputs. Bull. Am. Meteo. Soc., 78(11), 2539-2558.

Xie, S.P., H. Annamalai, F.A. Schott and J.P. McCreary, 2002: Structure and Mechanisms of South Indian Ocean Climate Variability. J. Climate, 15, 864-878.

Xu J. and J.C.L. Chan, 2001: The Role of the Asian-Australian Monsoon System in the Onset Time of El Niño Events. J. Climate, 14, 418-433.

Yamagata, T., and coauthors, 2002: The Indian Ocean dipole: A physical entity. Clivar Exch., 7 (2), 15-18.

Yasunari T., 1991: The monsoon year- A new concept of the climatic year in the tropics. Bull. Amer. Meteor. Soc., 72, 1331-1338.

Yu J.-Y., S.-P. Weng, and J.D. Farrara, 2003:Ocean Roles in the TBO Transitions of the Indian-Australian Monsoon System. J. Climate, 16, 3072-3080. 


\section{FIGURE CAPTIONS}

FIGURE 1: Composite analysis of February-March SST fields prior to positive/negative ENSO and TIOD events during the 1977-2001 period. (a) composite SST standardized anomalies over the Indian and Pacific Oceans for February-March prior to six El Niño years. (b), (c) and (d) same as (a), but for four La Niña, four positive TIOD and three negative TIOD years, respectively. Composites SST standardized anomalies significant at the $90 \%$ confidence level are shaded. See text for more details.

FIGURE 2: Composite analysis of February-March SST fields prior to strong/weak (Late) ISM years during the 1977-2001 period. (a) composite SST standardized anomalies over the Indian and Pacific Oceans for February-March prior to five weak ISM years. (b), (c) and (d) same as (a), but for five strong ISM, five weak and four strong Late ISM years, respectively. Composites SST standardized anomalies significant at the $90 \%$ confidence level are shaded. See text for more details.

FIGURE 3: Composite analysis of February-March SST fields prior to strong/weak AUSM and MCR years during the 1977-2001 period. (a) composite SST standardized anomalies over the Indian and Pacific Oceans for February-March prior to four weak AUSM years. (b), (c) and (d) same as (a), but for six strong AUSM, four weak MCR and five strong MCR years, respectively. Composites SST standardized anomalies significant at the 90\% confidence level are shaded. See text for more details.

FIGURE 4: Wavelet modulus analysis of the February-March SEIO SST time series.(a) The time series of SEIO SST (b) The local wavelet power spectrum of (a) using the Morlet wavelet. The left axis is the period (in year). The bottom axis is time (in year). Contours indicate the total variance at a particular frequency explained at a particular time in the time series. The thick contour encloses regions of greater than $90 \%$ confidence level for a whitenoise process. Cross-hatched regions on either end indicate the cone of influence where edge effects become important. Methods used are described in Torrence and Compo (1998).

FIGURE 5: Composite analysis of bimonthly SST fields with respect to eight cold SEIO SST years during the 1977-2001 period. The cold SEIO SST years are defined with the help of 
the February-March SEIO SST time series. (a), (b), (c), (d), (e), (f) composite SST standardized anomalies over the Indian and Pacific Oceans from February-March to December-January for the cold SEIO SST years. Composites SST standardized anomalies significant at the $90 \%$ confidence level are shaded. See text for more details.

FIGURE 6: Composite analysis of $850 \mathrm{hPa}$ wind $(\mathrm{m} / \mathrm{s})$, and $500 \mathrm{hPa}$ vertical pressure velocity $(\mathrm{Pa} / \mathrm{s})$ fields with respect to eight cold SEIO SST years from the NCEP reanalysis (1977-2001 period). See text for more details. (a), (b), (c), (d), (e) and (f) composite $850 \mathrm{hPa}$ wind $(\mathrm{m} / \mathrm{s})$, and $500 \mathrm{hPa}$ vertical pressure velocity $(\mathrm{Pa} / \mathrm{s})$ anomalies over the Indian and Pacific Oceans from February-March to December-January of the cold SEIO SST years, respectively. Only the $90 \%$ statistically significant $850 \mathrm{hPa}$ wind anomalies are shown.

FIGURE 7: Composite analysis of $200 \mathrm{hPa}$ wind $(\mathrm{m} / \mathrm{s})$, and $300 \mathrm{hPa}$ vertical pressure velocity $(\mathrm{Pa} / \mathrm{s})$ fields with respect to eight cold SEIO SST years from the NCEP reanalysis (1977-2001 period). See text for more details. (a), (b), (c), (d), (e) and (f) composite $200 \mathrm{hPa}$ wind $(\mathrm{m} / \mathrm{s})$, and $300 \mathrm{hPa}$ vertical pressure velocity $(\mathrm{Pa} / \mathrm{s})$ anomalies over the Indian and Pacific Oceans from February-March to December-January of the cold SEIO SST years, respectively. Only the $90 \%$ statistically significant $200 \mathrm{hPa}$ wind anomalies are shown.

FIGURE 8: Composite analysis of April-May SLP, latent heat flux and rainfall fields with respect to eight cold SEIO SST years from the NCEP reanalysis (1977-2001 period). See text for more details. (a) April-May composite SLP standardized anomalies over the Indian and Pacific Oceans for the cold SEIO SST years, (b) probability map showing critical probabilities associated with the composite map in (a). Only the 10,1,0.1\% confidence levels are plotted. (c) and (d) same as (a) and (b), but for latent heat flux. (e) and (f) same as (a) and (b), but for rainfall.

FIGURE 9: Same as Figure 5, but for six warm SEIO SST years during the 1977-2001 period.

FIGURE 10: Same as Figure 6, but for six warm SEIO SST years during the 1977-2001 period. 
FIGURE 11: Lead-lag correlation of monthly Niño3.4 SST index with February-March SEIO SST (solid circles), WPAC $850 \mathrm{hPa}$ zonal wind (open squares), Z20 (open triangles) and Niño3.4 SST (stars) indices during the 1977-2001 period. Note that opposite correlation coefficients between Niño3.4 and SEIO SST indices have been represented in order to facilitate the comparison between the various ENSO predictors. The lead-lag correlations of monthly SEIO SST time series with February-March SEIO SST index (crosses) are also plotted. Also shown are 95\% confidence levels. See text for the definition of the indices.

FIGURE 12: Lead-lag correlation of October-December Niño3.4 SST index with monthly SEIO SST (open circles), WPAC $850 \mathrm{hPa}$ zonal wind (solid squares), EAUS $850 \mathrm{hPa}$ meridional wind (solid diamonds) and Z20 (open triangles) indices during the 1977-2001 period. Note that opposite correlation coefficients between Niño3.4 and SEIO SST indices have been represented in order to facilitate the comparison between the various ENSO predictors. Also shown are 95\% confidence levels. See text for the definition of the indices.

FIGURE 13: Lead-lag correlations of monthly values of WPAC 850 and $200 \mathrm{hPa}$ zonal wind with February-March SEIO SST (solid circles and solid triangles), monthly WPAC $850 \mathrm{hPa}$ zonal wind with February-March WPAC 850 hPa zonal wind (crosses), monthly WPAC 200 hPa zonal wind with February-March WPAC 200 hPa zonal wind (stars). Also shown are 95\% confidence levels. See text for the definition of the indices.

FIGURE 14: Lead-lag correlations of monthly ETIO SST (solid circles), WTIO SST (open circles), TIOD SST (solid squares) and equatorial Indian Ocean $850 \mathrm{hPa}$ zonal wind (open triangles) time series with February-March SEIO SST index during the 1977-2001 period. Also shown are 95\% confidence levels. See text for the definition of the indices. 


\section{TABLE CAPTIONS}

Table 1: Description of the various indices used in the composite analyses.

Table 2: Correlation coefficients of various rainfall and dynamical ISM, MCR and AUSM indices with February-March SEIO SST index for June-July, August-September, SeptemberNovember and December-February seasons during the 1977-2001 period.. Coefficients significant at the 90, 95 and 99\% levels are marked with one, two and three stars, respectively. WSI1 is a westerly shear indice between standardized zonal wind anomalies at 850 and $200 \mathrm{hPa}$ averaged over the region $5^{\circ} \mathrm{N}-20^{\circ} \mathrm{N} / 40^{\circ} \mathrm{E}-80^{\circ} \mathrm{E}$. SSI 1 is a southerly shear index between standardized meridional wind anomalies at 850 and $200 \mathrm{hPa}$ averaged over the following areas: $15^{\circ} \mathrm{N}-30^{\circ} \mathrm{N} / 85^{\circ} \mathrm{E}-100^{\circ} \mathrm{E}$ and $0-15^{\circ} \mathrm{S} / 40^{\circ} \mathrm{E}-55^{\circ} \mathrm{E}$. DU1 is the difference between standardized $850 \mathrm{hPa}$ zonal wind anomalies area-averaged over a southern region : $5^{\circ} \mathrm{N}-15^{\circ} \mathrm{N} / 40^{\circ} \mathrm{E}-80^{\circ} \mathrm{E}$ and a northern region $20^{\circ} \mathrm{N}-30^{\circ} \mathrm{N} / 70^{\circ} \mathrm{E}-90^{\circ} \mathrm{E}$. WSI 1 , SSI 1 and DU1 are dynamical ISM indices. More details about these indices and their constructions may be found in Wang and Fan (1999) and Wang et al. (2001). Rainfall AIRI, MCR and AUSM indices are defined in text. 


\begin{tabular}{|c|c|c|c|c|c|c|c|c|}
\hline & & $\begin{array}{l}\text { ENSO Extreme events } \\
\text { (El Niño and La Niña) }\end{array}$ & $\begin{array}{l}\text { Indian Summer } \\
\text { Monsoon (ISM) }\end{array}$ & $\begin{array}{l}\text { Late Indian Summer } \\
\text { Monsoon (Late ISM) }\end{array}$ & $\begin{array}{l}\text { AUstralian Summer } \\
\text { Monsoon (AUSM) }\end{array}$ & $\begin{array}{l}\text { Maritime Continent } \\
\text { Rainfall (MCR) }\end{array}$ & $\begin{array}{c}\text { Tropical Indian } \\
\text { Ocean Dipole (TIOD) } \\
\text { events }\end{array}$ & $\begin{array}{l}\text { South East Indian Ocean } \\
\text { (SEIO) }\end{array}$ \\
\hline \multicolumn{2}{|c|}{ Index name } & Niño 3.4 Index & $\begin{array}{l}\text { All India Rainfall Index } \\
\text { (AIRI) }\end{array}$ & $\begin{array}{c}\text { All India Rainfall Index } \\
\text { (AIRI) }\end{array}$ & $\begin{array}{l}\text { AUSM Index } \\
\text { (Meehl and } \\
\text { Arblaster, 2002) }\end{array}$ & MCR index & $\begin{array}{c}\text { TIOD Index } \\
\text { (Saji and al., 1999) }\end{array}$ & $\begin{array}{c}\text { SEIO Index } \\
\text { (Terray et al., 2003) }\end{array}$ \\
\hline & Data & $\begin{array}{c}\text { SST } \\
\text { (ERSST ; Smith and } \\
\text { Reynolds, 2003) }\end{array}$ & $\begin{array}{c}\text { Rainfall 6-9 } \\
\text { (Partasarathy, 1995) }\end{array}$ & $\begin{array}{c}\text { Rainfall 8-9 } \\
\text { (Partasarathy, 1995) }\end{array}$ & $\begin{array}{c}\text { Rainfall 12-2 } \\
\text { (CMAP ; } \\
\text { Xie and Arkin, 1997) }\end{array}$ & $\begin{array}{c}\text { Rainfall 6-9 } \\
\text { (CMAP ; } \\
\text { Xie and Arkin, 1997) }\end{array}$ & $\begin{array}{c}\text { SST 9-11 } \\
\text { (ERSST ; Smith and } \\
\text { Reynolds, 2003) }\end{array}$ & $\begin{array}{l}\text { SST (ERSST; } \\
\text { Smith and Reynolds, 2003) }\end{array}$ \\
\hline \multicolumn{2}{|c|}{ Geographical Domain } & $5^{\circ} \mathrm{N}-5^{\circ} \mathrm{S} / 190^{\circ} \mathrm{E}-240^{\circ} \mathrm{E}$ & Indian subcontinent & Indian Subcontinent & $\begin{array}{l}100^{\circ} \mathrm{E}-150^{\circ} \mathrm{E} / \\
5^{\circ} \mathrm{N}-20^{\circ} \mathrm{S}\end{array}$ & $\begin{array}{c}6,25^{\circ} \mathrm{N}-6,25^{\circ} \mathrm{S} / \\
111.25^{\circ} \mathrm{E}-141.25^{\circ} \mathrm{E}\end{array}$ & $\begin{array}{c}50^{\circ} \mathrm{E}-70^{\circ} \mathrm{E} / 10^{\circ} \mathrm{N}-10^{\circ} \mathrm{S} \\
\text { minus } \\
90^{\circ} \mathrm{E}-110^{\circ} \mathrm{E} / 10^{\circ} \mathrm{S}-0\end{array}$ & $72^{\circ} \mathrm{E}-122^{\circ} \mathrm{E} / 4^{\circ} \mathrm{S}-26 \mathrm{~S}$ \\
\hline \multicolumn{2}{|c|}{ Period } & $1977-2001$ & $1977-2001$ & $1977-2001$ & $1979-2001$ & $1979-2001$ & $1977-2001$ & $1977-2001$ \\
\hline \multirow{2}{*}{$\begin{array}{l}\text { Composites } \\
\text { Years }\end{array}$} & $\begin{array}{l}\text { Warm, weak or } \\
\text { positive Events }\end{array}$ & $\begin{array}{l}\text { 1979, 1982, 1986, } \\
1991,1994,1997\end{array}$ & $\begin{array}{l}\text { 1979, 1982, 1985, } \\
1986,1987\end{array}$ & $\begin{array}{l}1979,1986,1991 \\
2000,2001\end{array}$ & $\begin{array}{l}1982,1989,1991, \\
1997\end{array}$ & $\begin{array}{l}\text { 1982, 1987, 1991, } \\
1994,1997\end{array}$ & $\begin{array}{l}1977,1982,1994, \\
1997\end{array}$ & $\begin{array}{l}1983,1985,1988 \\
1996,1998\end{array}$ \\
\hline & $\begin{array}{l}\text { Cold, strong or } \\
\text { negative Events }\end{array}$ & $\begin{array}{l}1984,1988,1995 \\
1998\end{array}$ & $\begin{array}{l}1978,1983,1988 \\
1990,1994\end{array}$ & $\begin{array}{l}1983,1988,1990 \\
1998\end{array}$ & $\begin{array}{l}1980,1983,1996 \\
1998,1999,2000\end{array}$ & $\begin{array}{l}1983,1984,1985 \\
1988,1999\end{array}$ & $1990,1996,1998$ & $\begin{array}{l}\text { 1977, 1979, 1981, 1982, } \\
1986,1993,1994,1997,2001\end{array}$ \\
\hline
\end{tabular}

Table 1 : Description of the different indices used in the composite analyses. 


\begin{tabular}{|l|c|c|c|c|c|c|c|c|}
\hline Season & \multicolumn{2}{|c|}{$6-7$} & \multicolumn{2}{|c|}{$8-9$} & \multicolumn{3}{c|}{$9-11$} & \multicolumn{2}{c|}{$12-2$} \\
\hline AIRI & 0,00 & & 0,61 & $(* * *)$ & 0,50 & $(* *)$ & $-0,05$ & \\
\hline Westerly Shear Index 1 (WSI 1) & 0 & & 0,56 & $(* * *)$ & 0,67 & $(* * *)$ & 0,22 & \\
\hline Southerly Shear Index 1 (SSI 1) & 0,02 & & 0,66 & $(* * *)$ & 0,34 & $(*)$ & $-0,27$ & \\
\hline DU1 & 0,08 & & 0,52 & $(* *)$ & 0,73 & $(* * *)$ & $-0,09$ & \\
\hline Maritime Continent Rainfall (MCR) & 0,43 & $(* *)$ & 0,70 & $(* * *)$ & 0,62 & $(* * *)$ & 0,57 & $(* * *)$ \\
\hline Australian Monsoon Rainfall & 0,41 & $(*)$ & 0,64 & $(* * *)$ & 0,57 & $(* * *)$ & 0,53 & $(* * *)$ \\
\hline
\end{tabular}

Table 2 
Figure 1
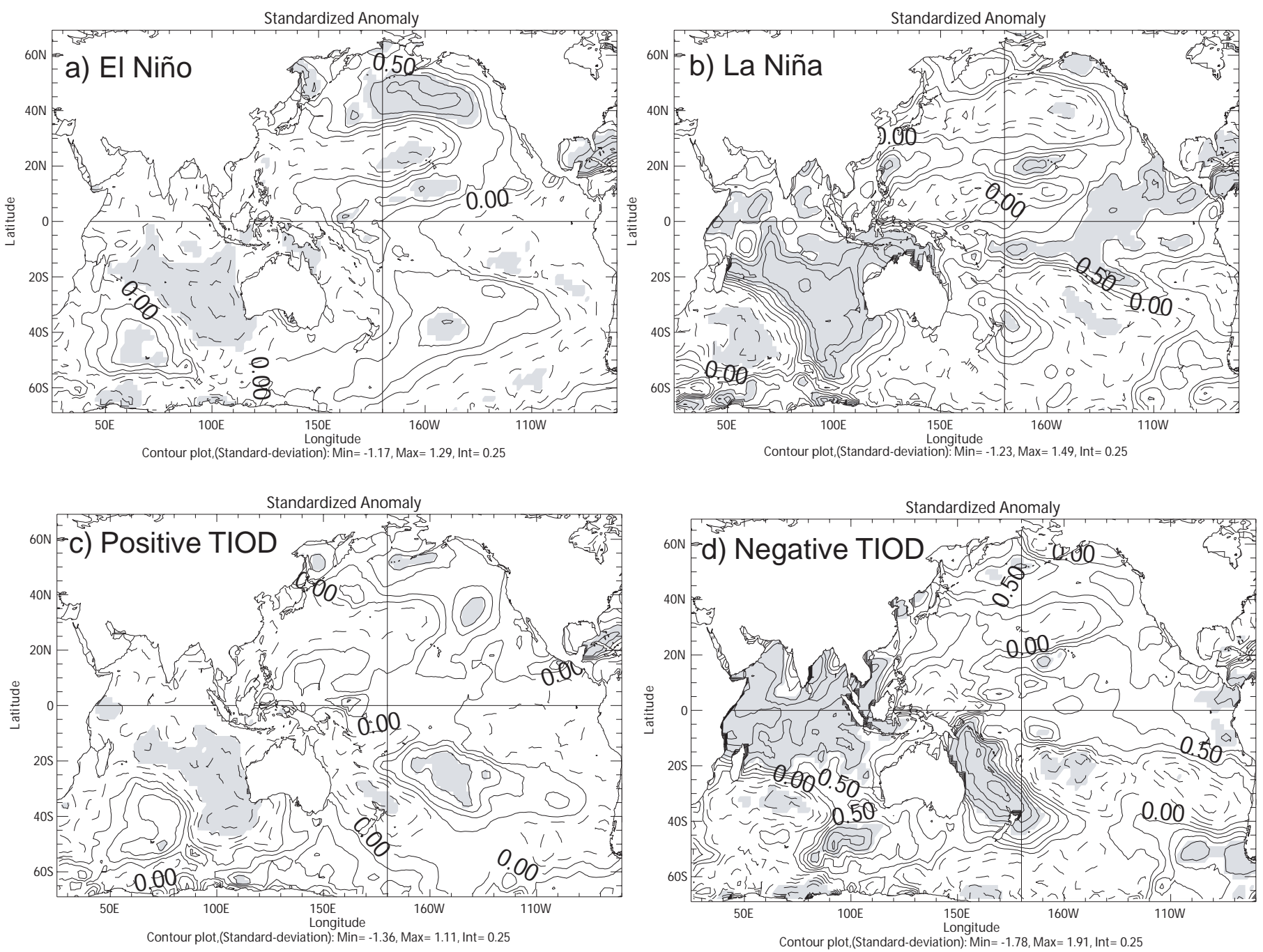

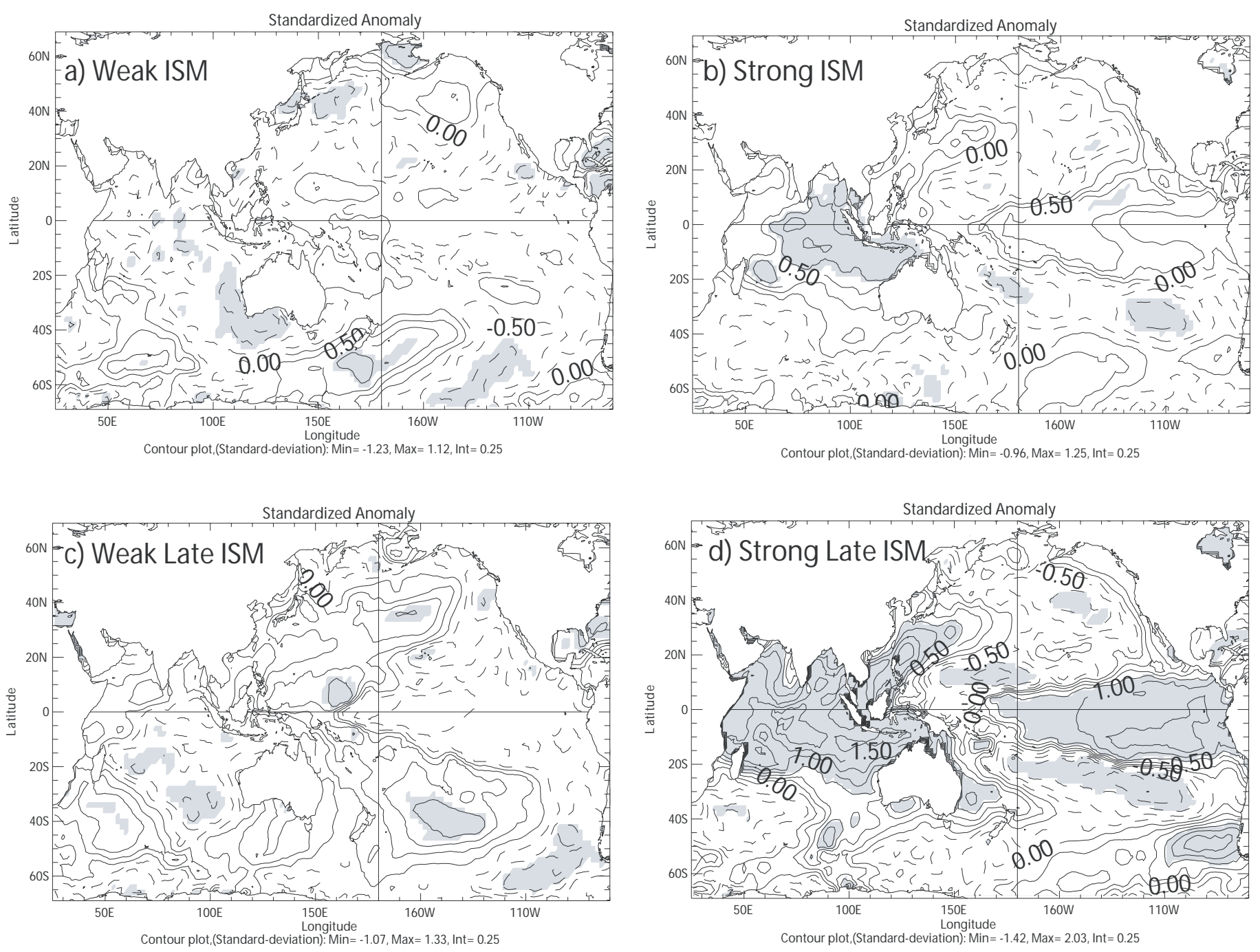

Figure 2 

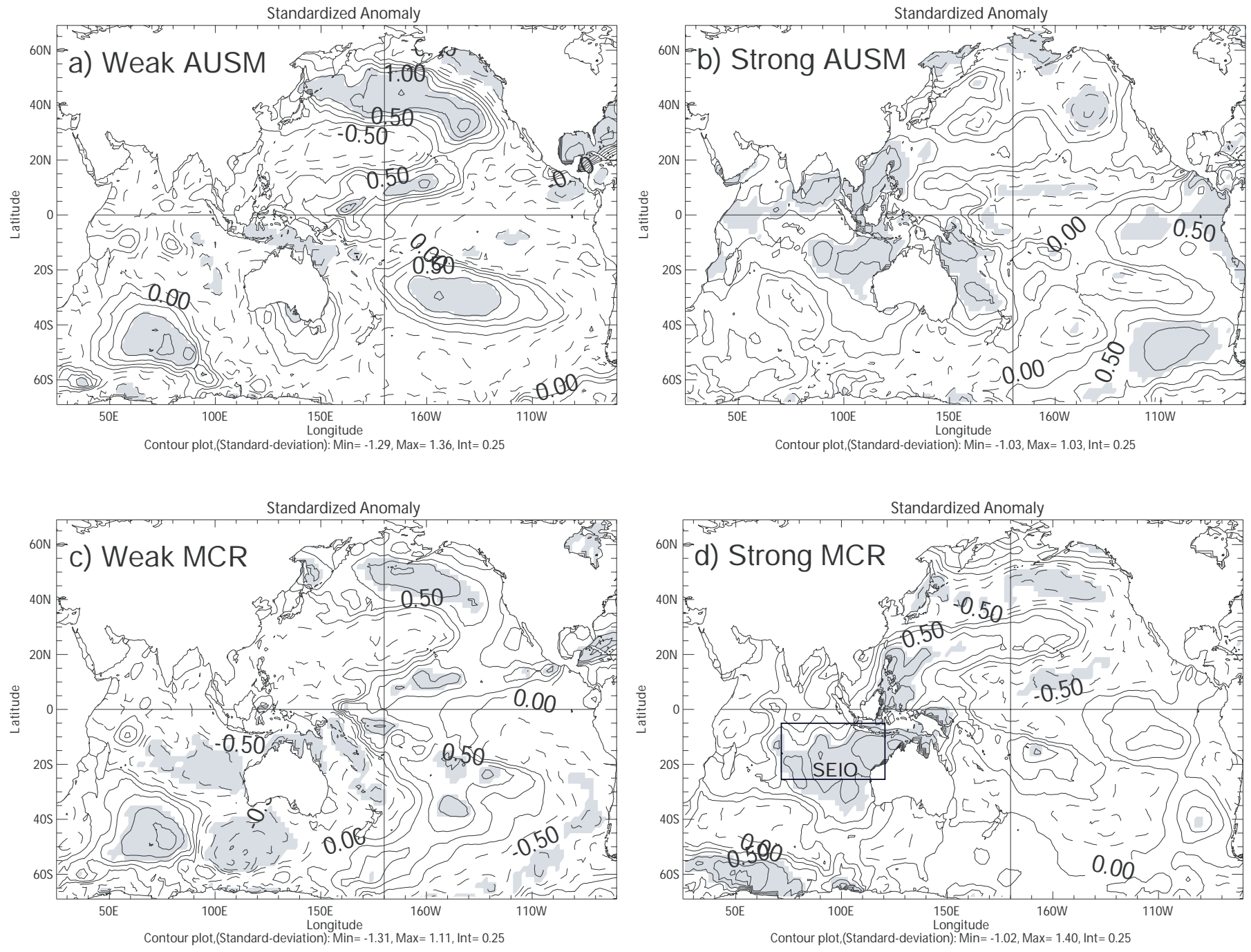

Figure 3 
Figure 4

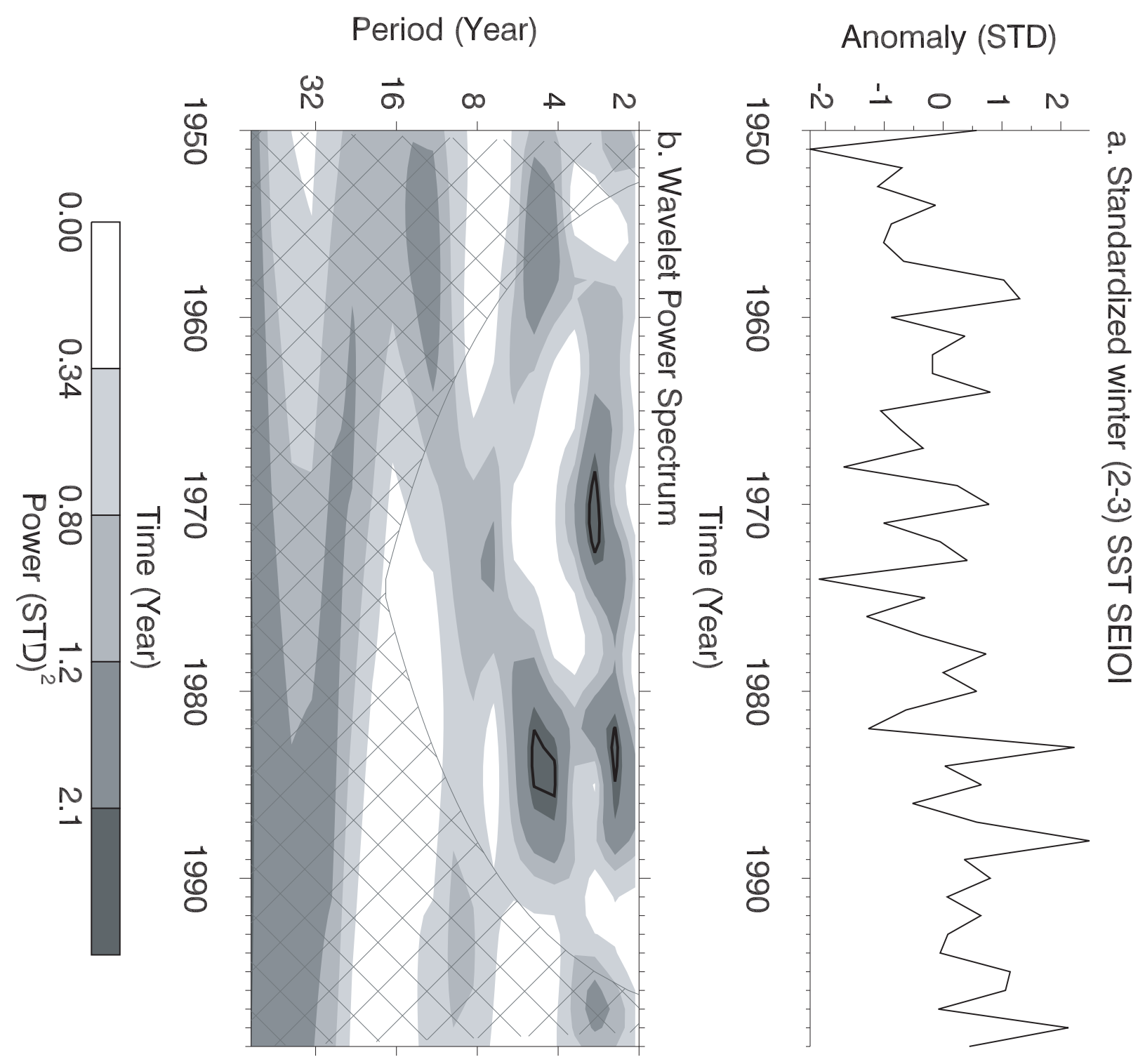


Figure 5

Cold SEIO SST Composites SST - ERSST (1977-2001) - $\quad$ Year 0
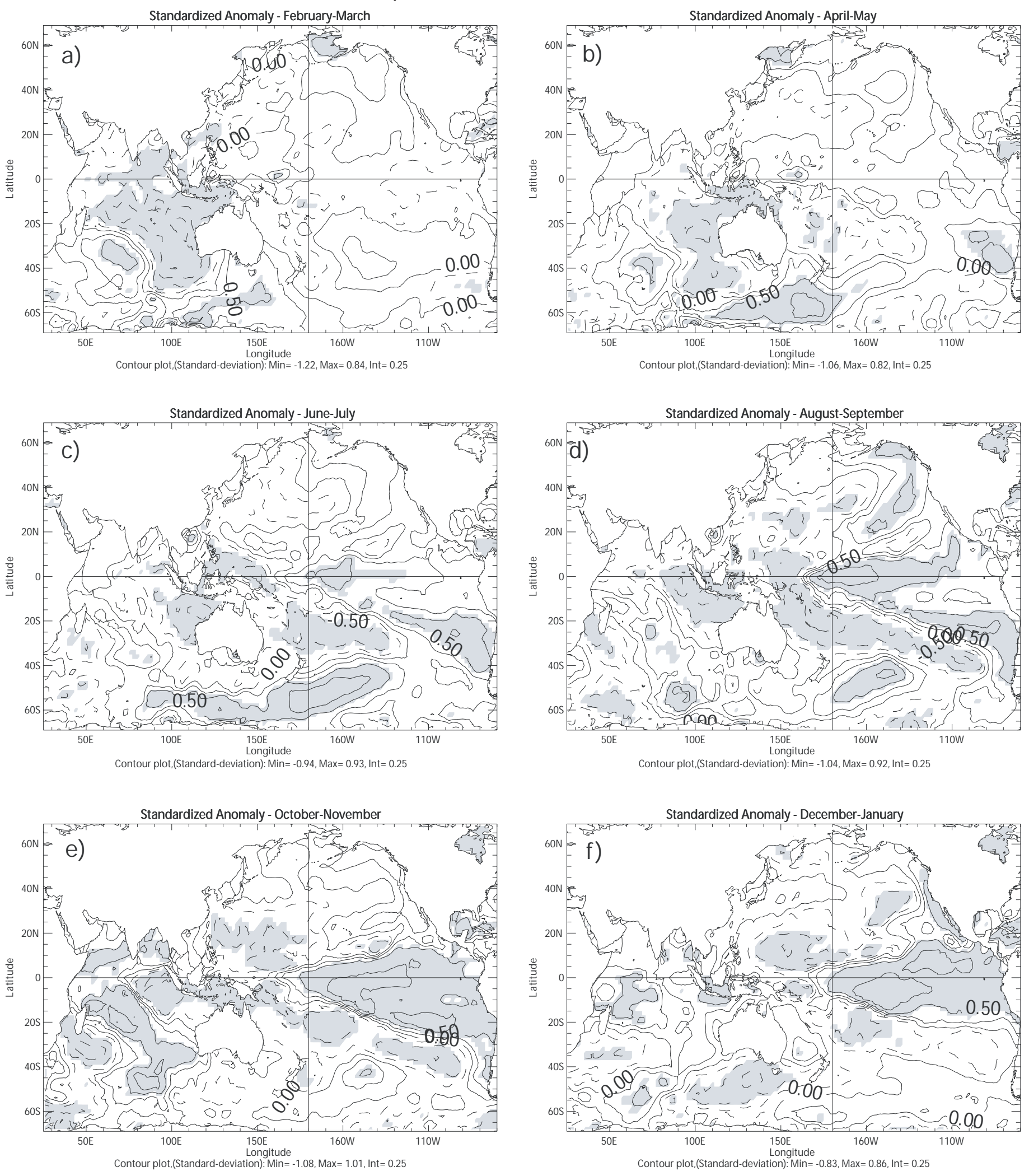
Figure 6

Cold SEIO SST Composites - 850 hPa wind and 500 hPa Omega - NCEP (1977-2001) - Year 0

a)

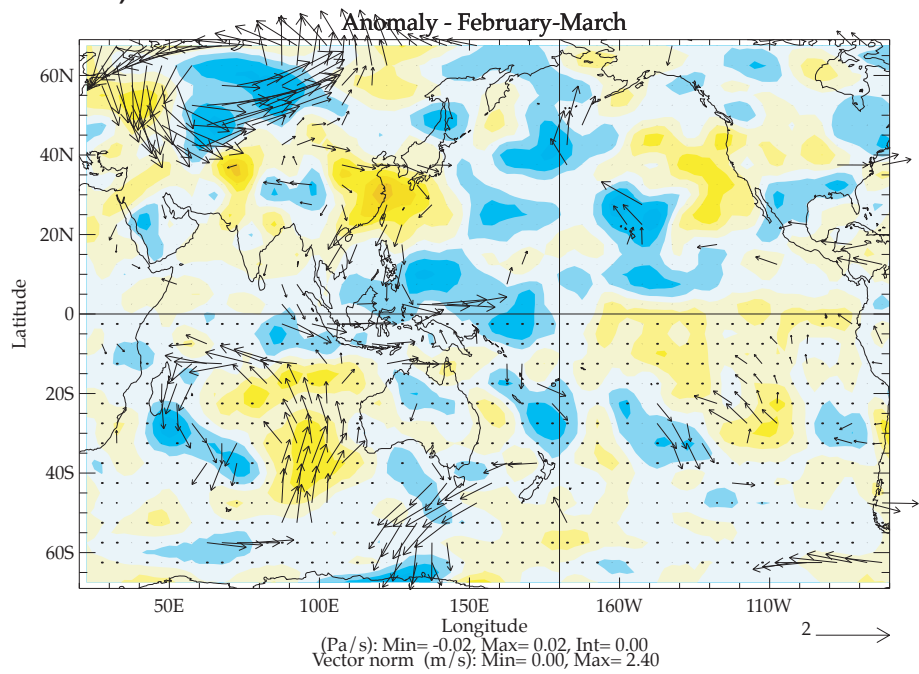

c)

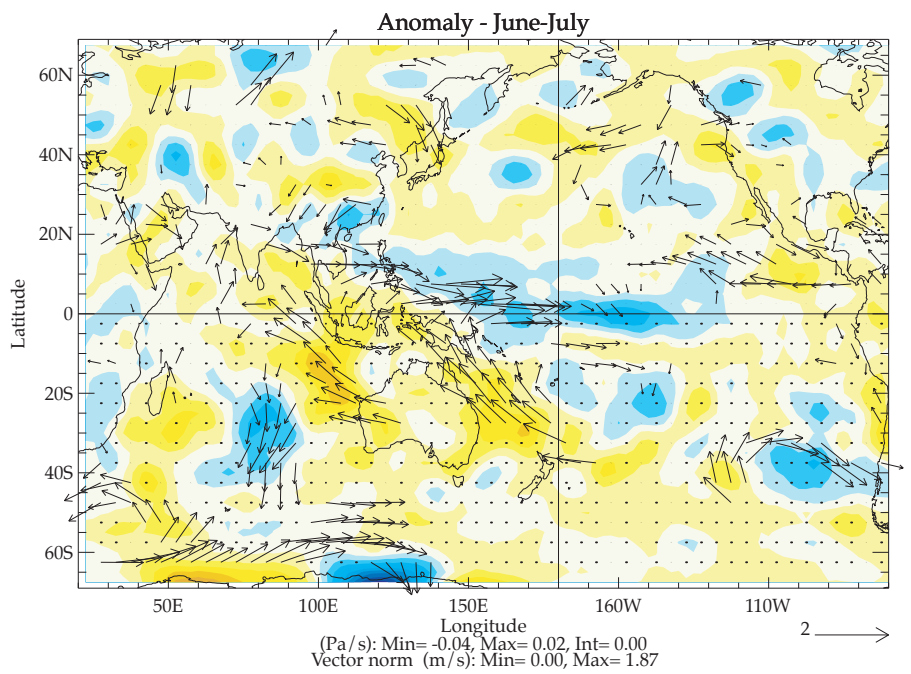

e)

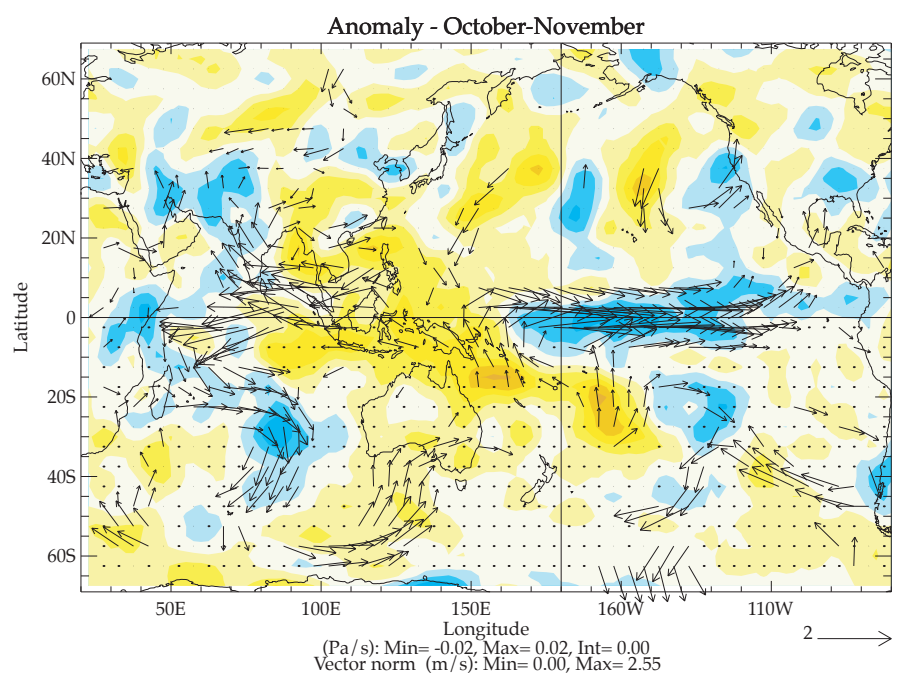

b)

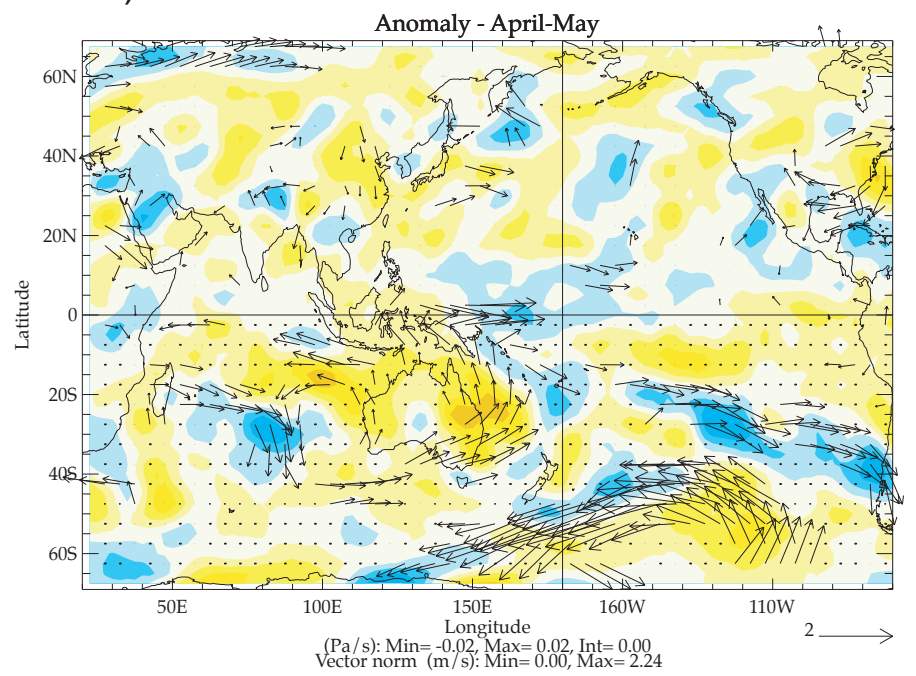

d)

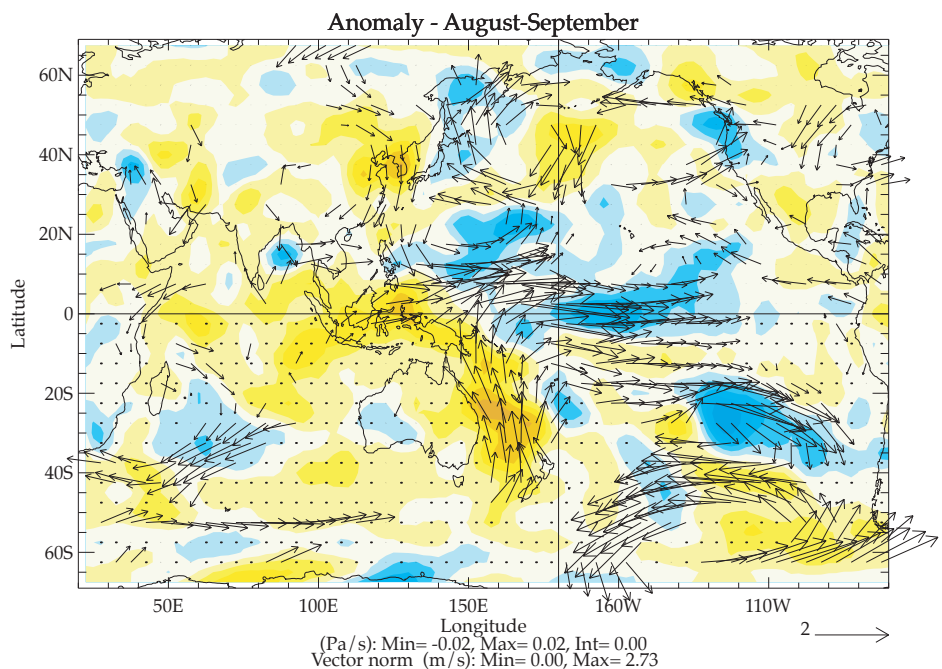

f)

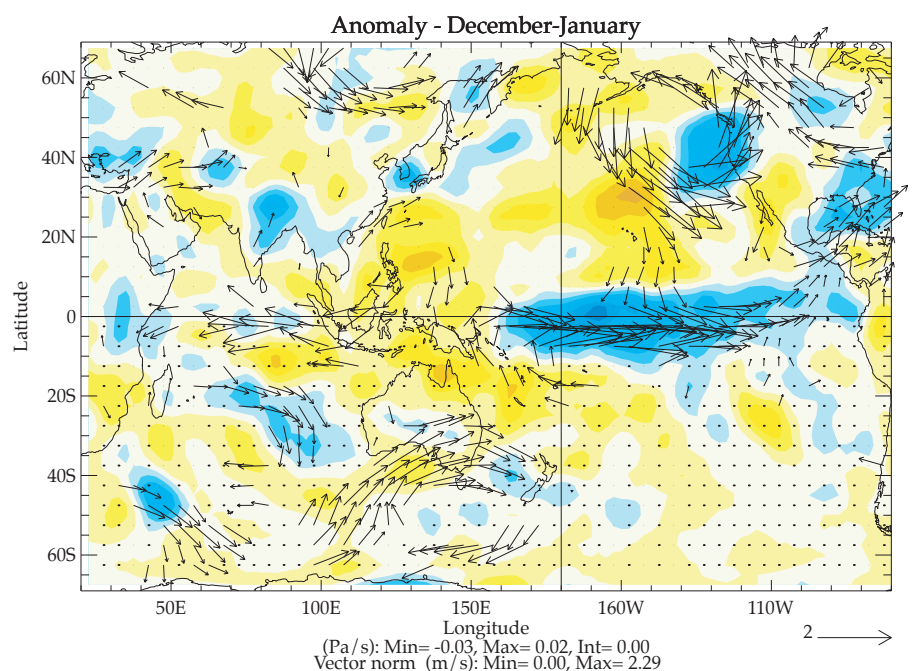




\section{Figure 7}

Cold SEIO SST Composites - $200 \mathrm{hPa}$ wind and 300 hPa Omega - NCEP (1977-2001) - Year 0

a)

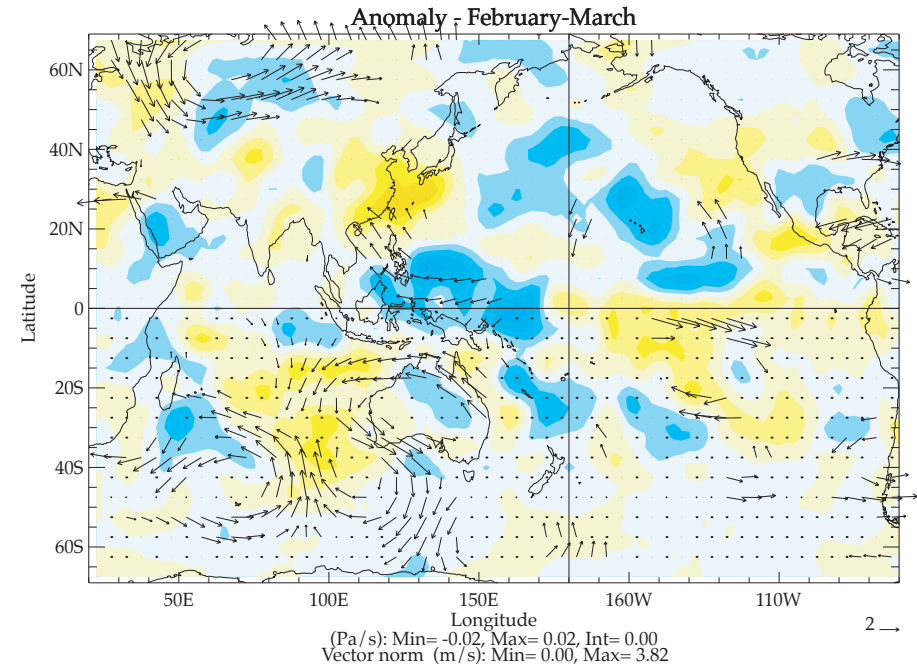

c)

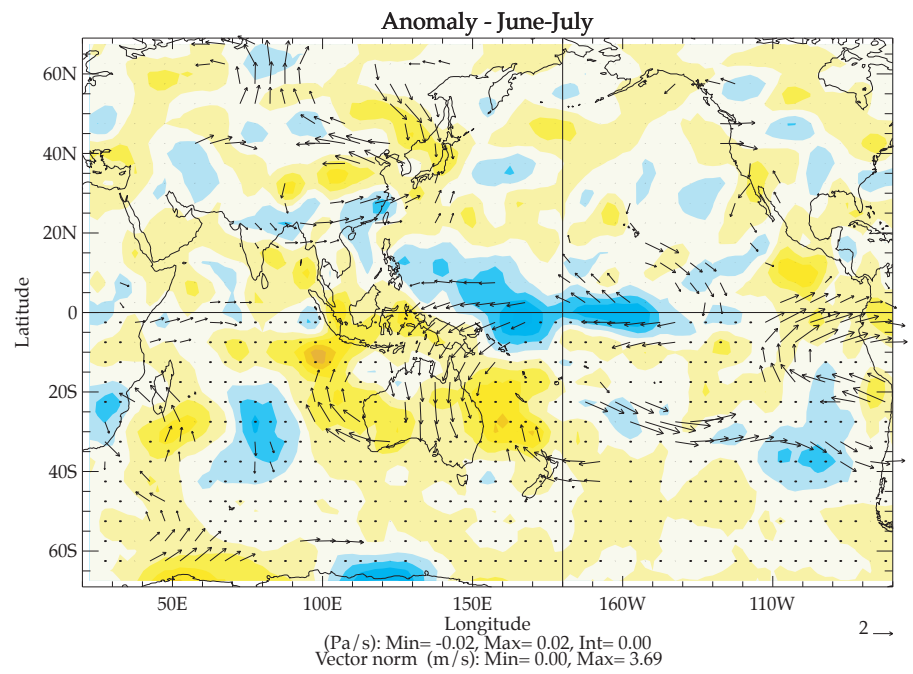

e)

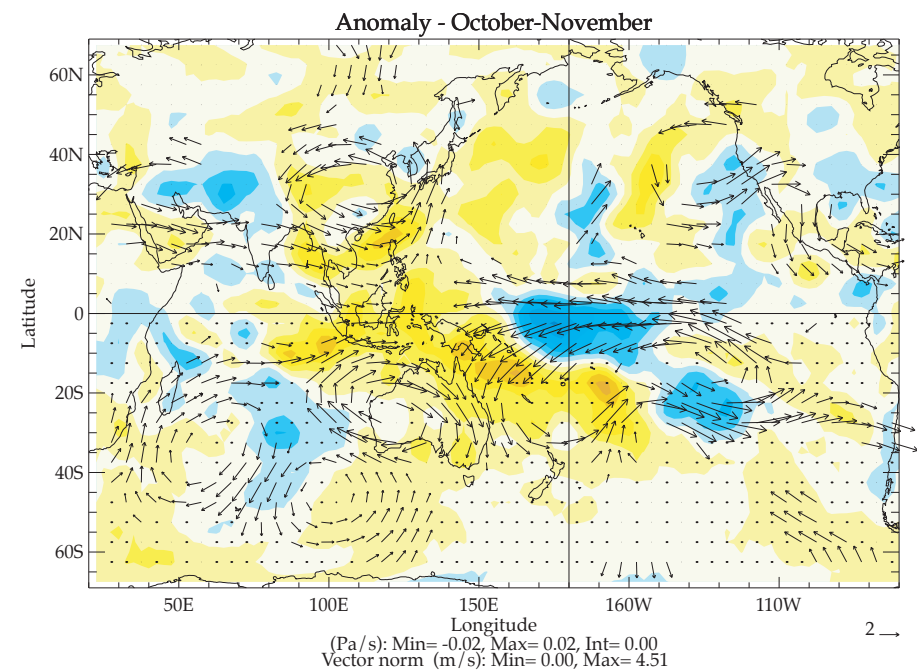

b)

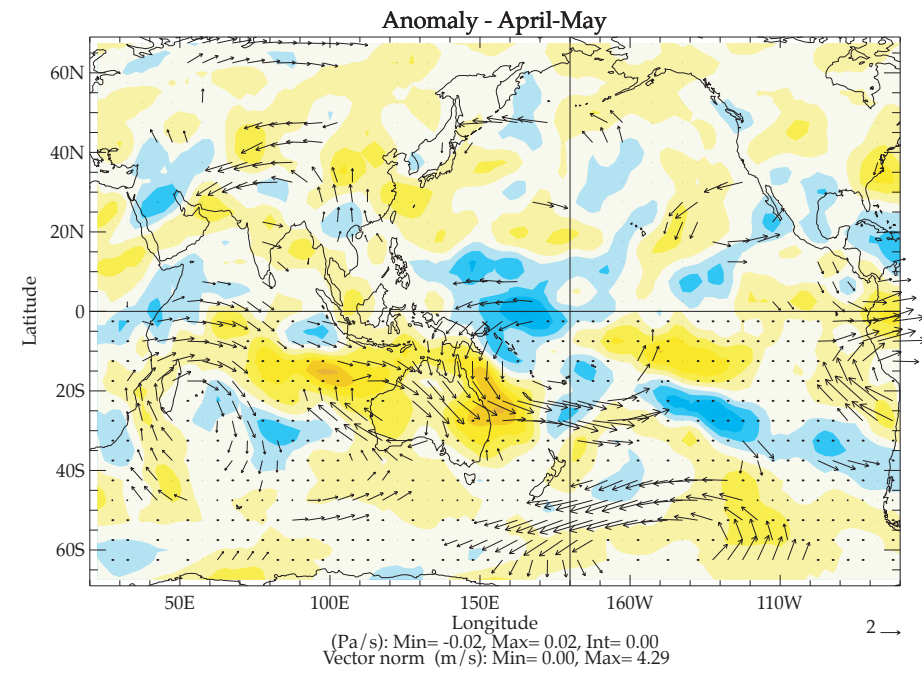

d)

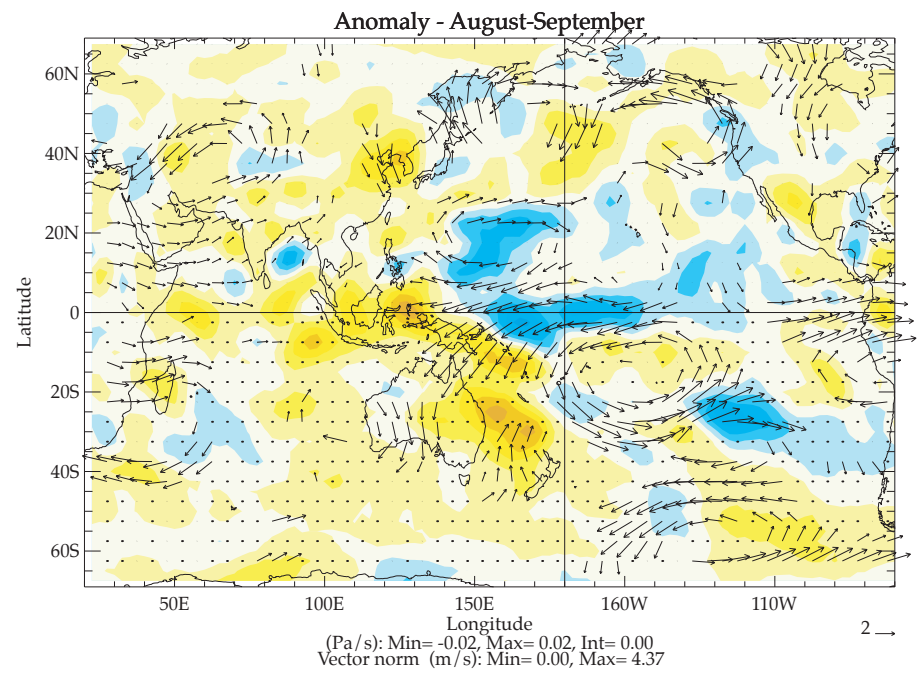

f)

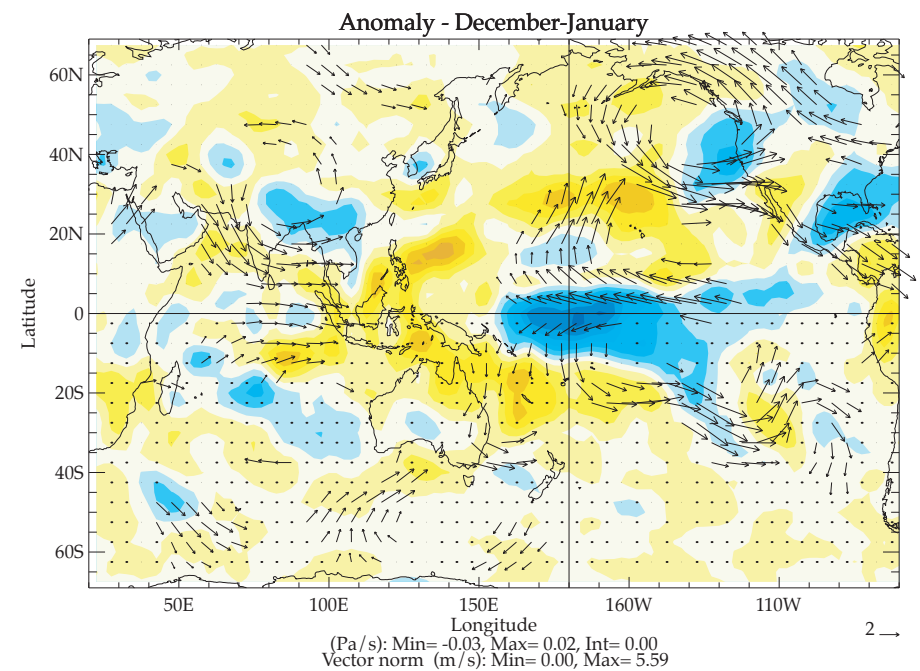


Figure 8

a)

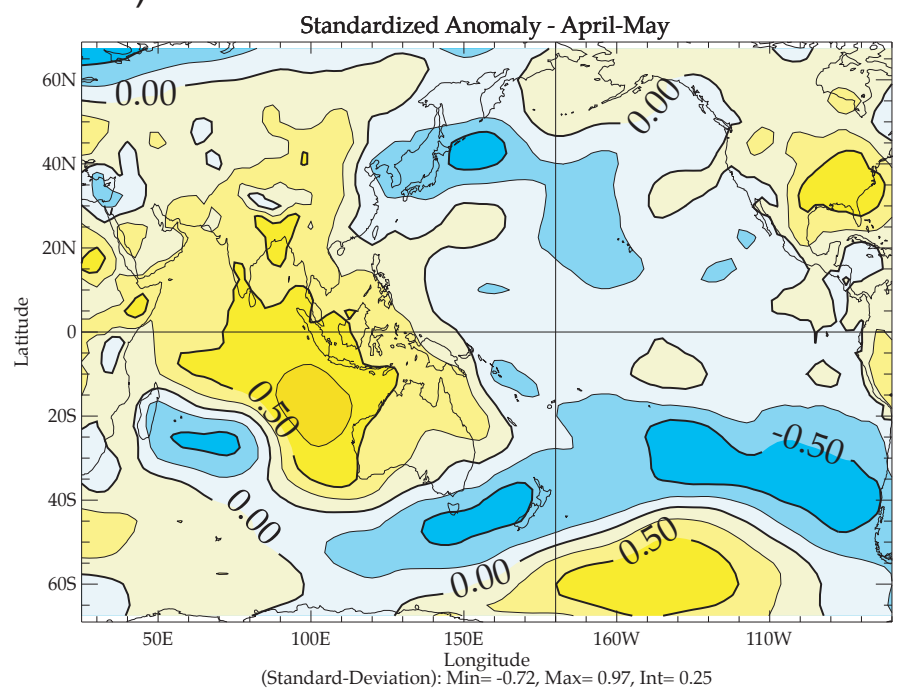

(Standard-Deviation): Min $=-0.72, \operatorname{Max}=0.97, \operatorname{Int}=0.25$ Cold SEIO SST Composites - SLP - NCEP (1977-2001) - Year 0

b)

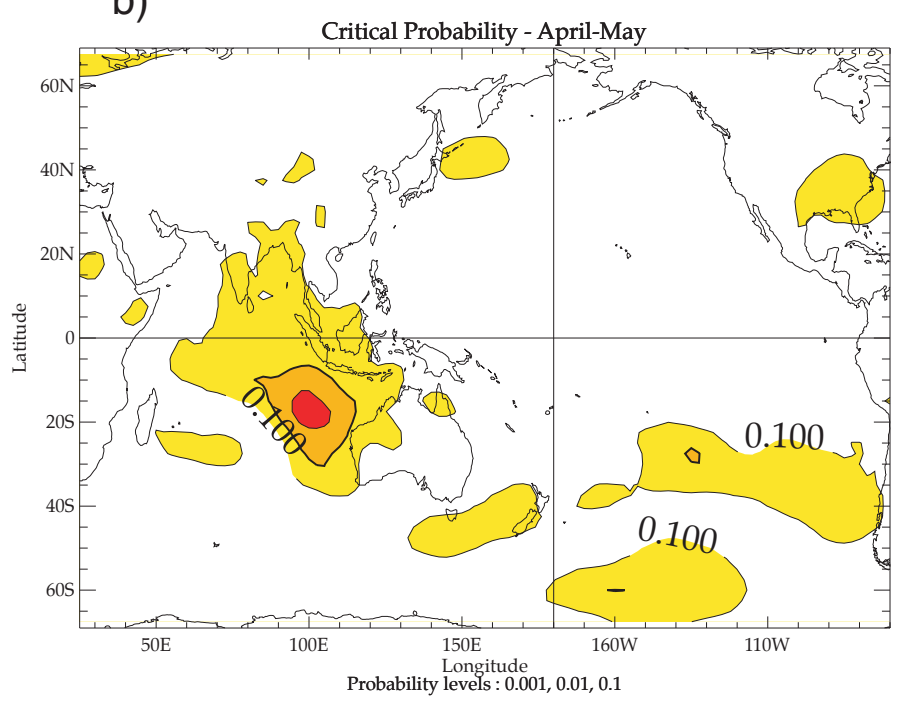

c)

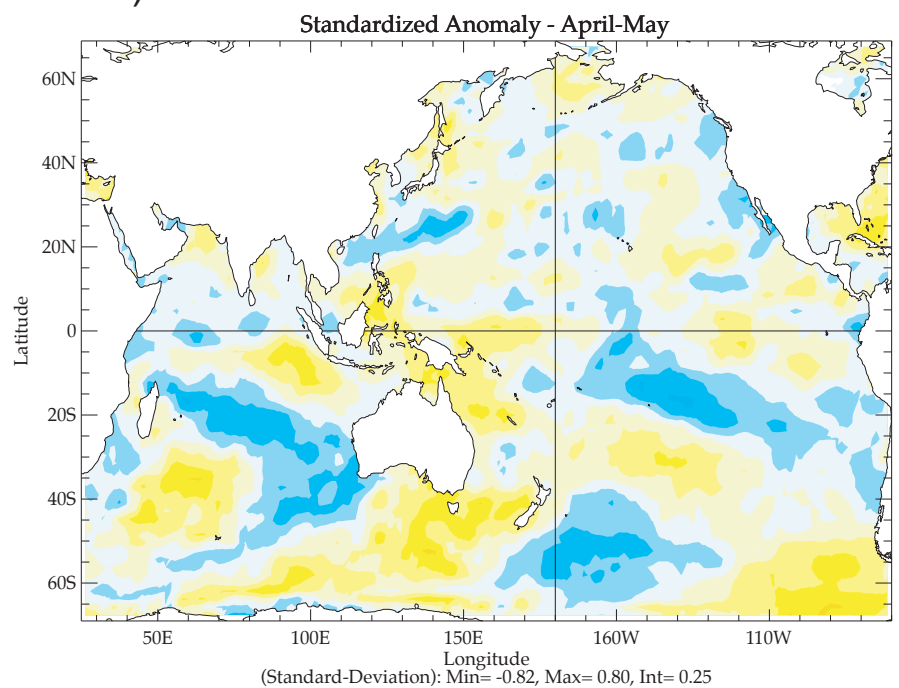

$\begin{aligned} \text { Longitude } & \\ \text { (Standard-Deviation): } & \text { Min }=-0.82, \operatorname{Max}=0.80, \text { Int }=0.25\end{aligned}$

Cold SEIO SST Composites - Latent Heat Flux - NCEP (1977-2001) - Year 0

d)

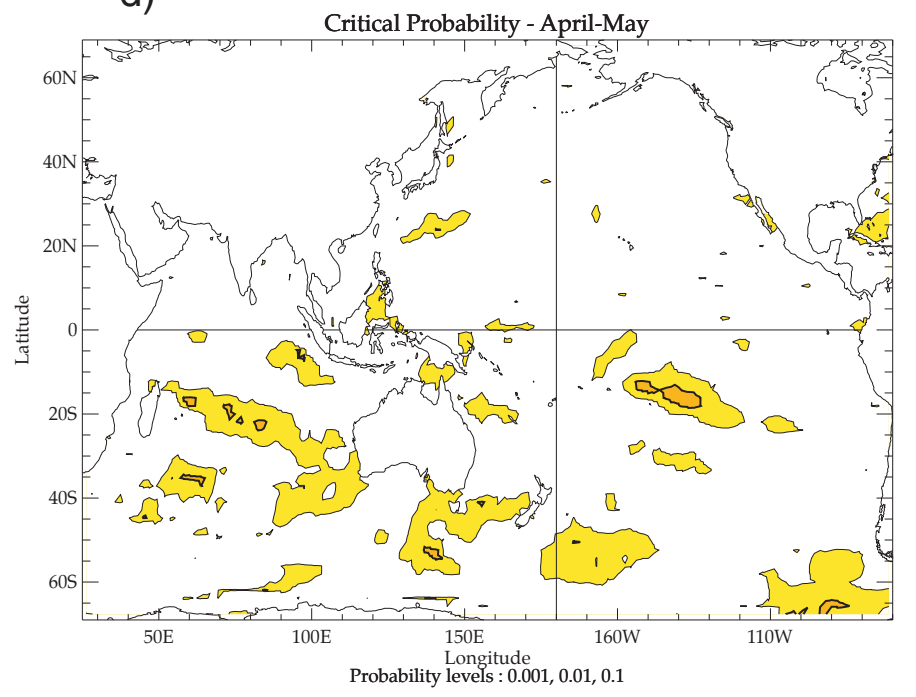

e)

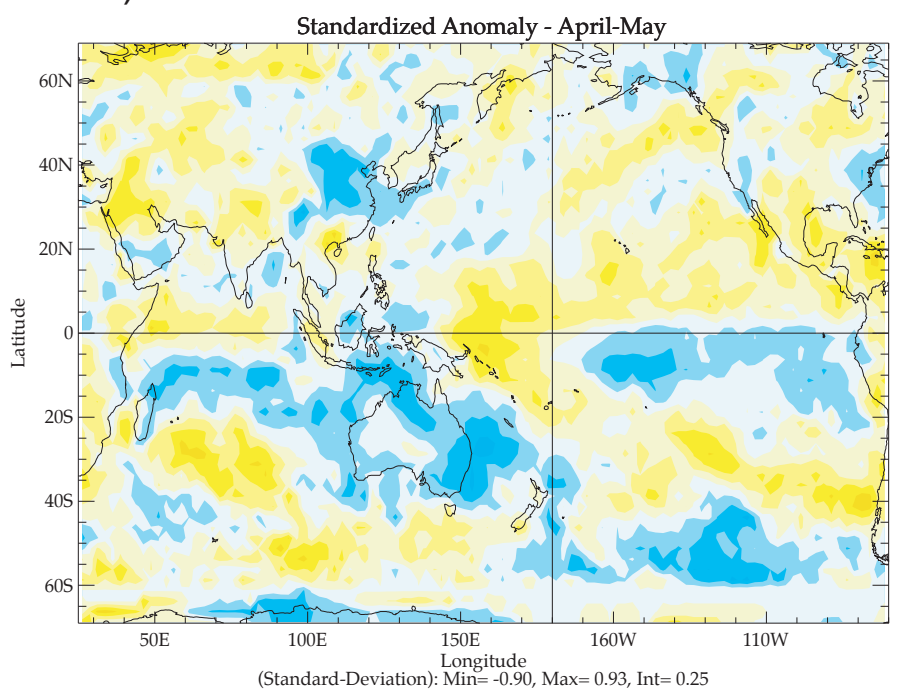

f)

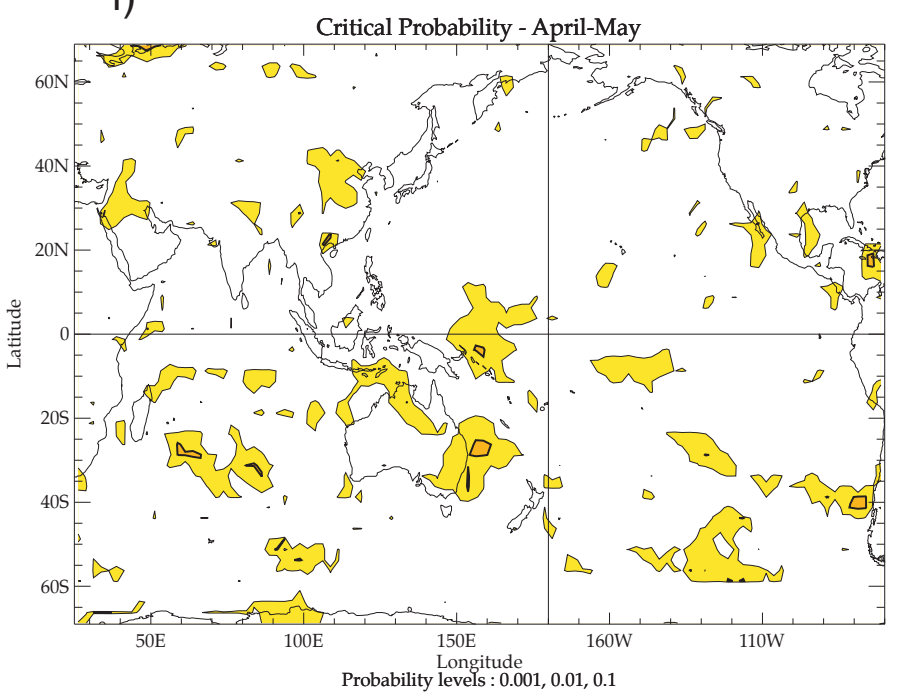


Figure 9

Warm SEIO SST Composites SST - ERSST (1977-2001) - Year 0
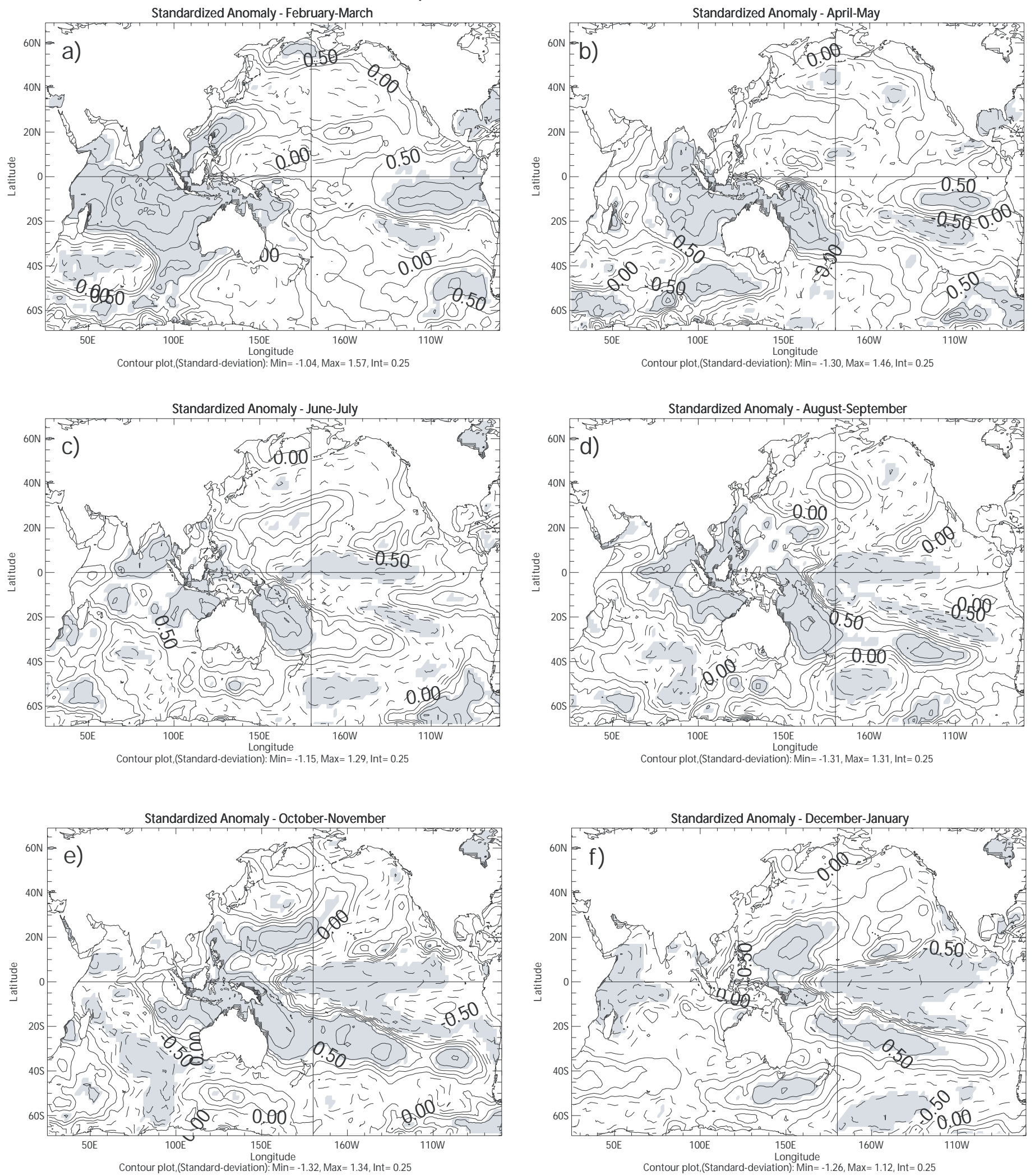


\section{Figure 10}

Warm SEIO SST Composites - $850 \mathrm{hPa}$ wind and $500 \mathrm{hPa}$ Omega - NCEP (1977-2001) - Year 0

a)

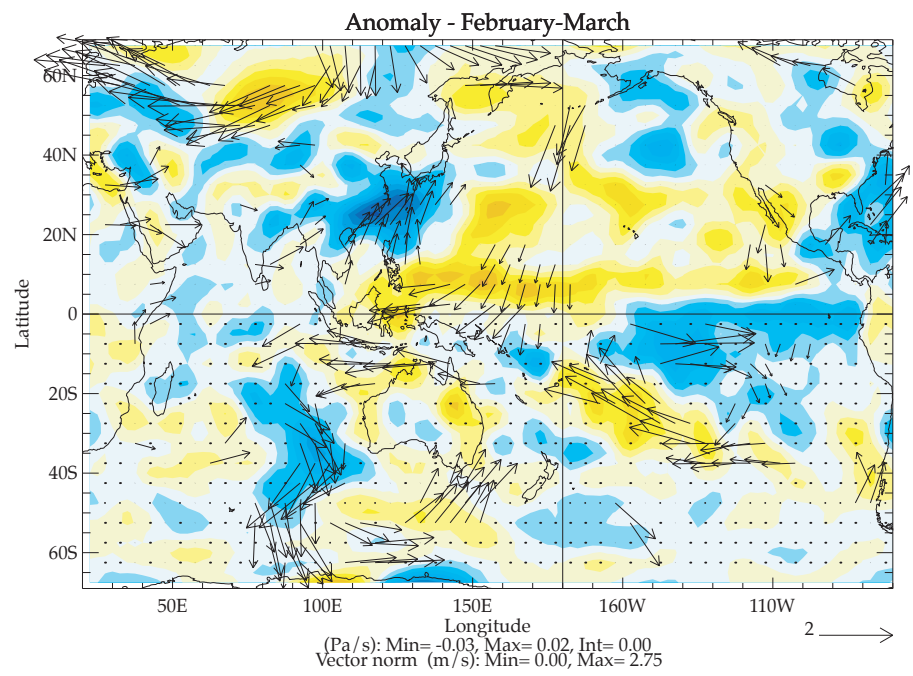

c)

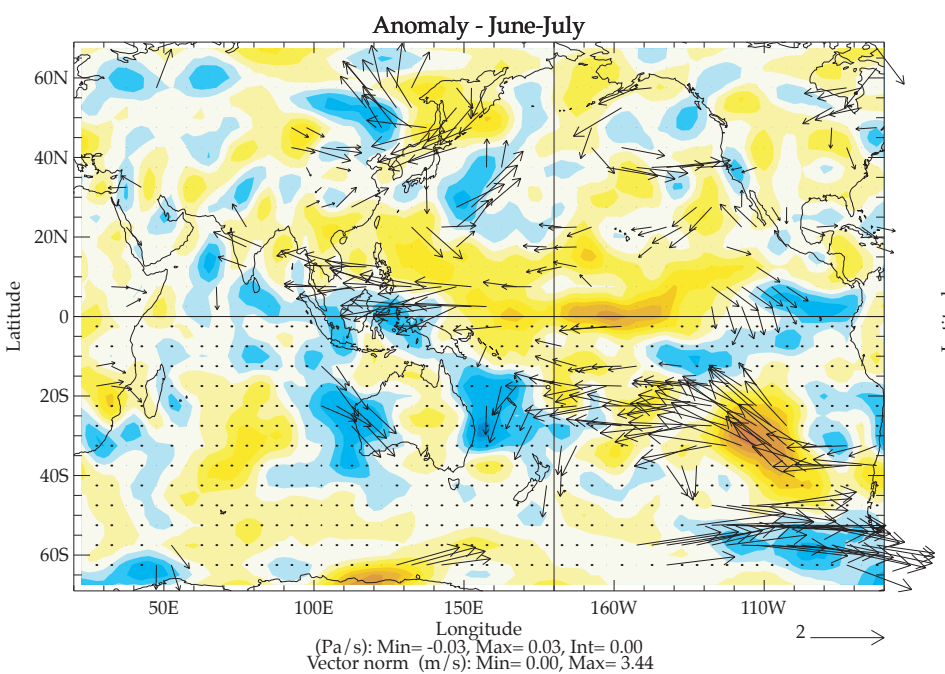

e)

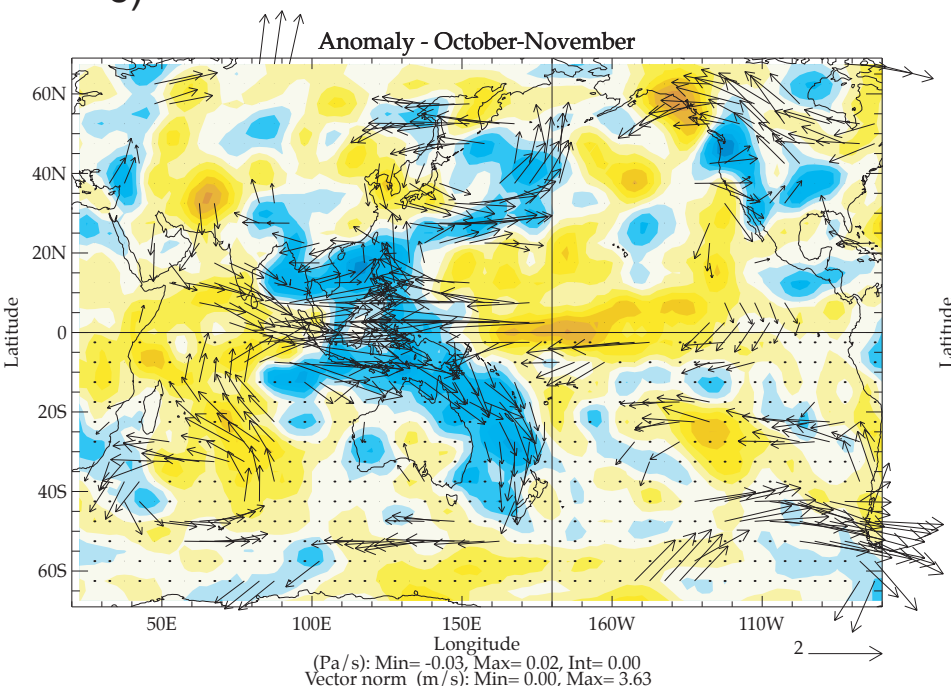

Longitude
$\begin{gathered}(\mathrm{Pa} / \mathrm{s}): \mathrm{Min}=-0.03, \mathrm{Max}=0.02, \mathrm{Int}=0.00 \\ \text { Vector norm }(\mathrm{m} / \mathrm{s}): \text { : Min }=0.00, \operatorname{Max}=3.63\end{gathered}$ b)
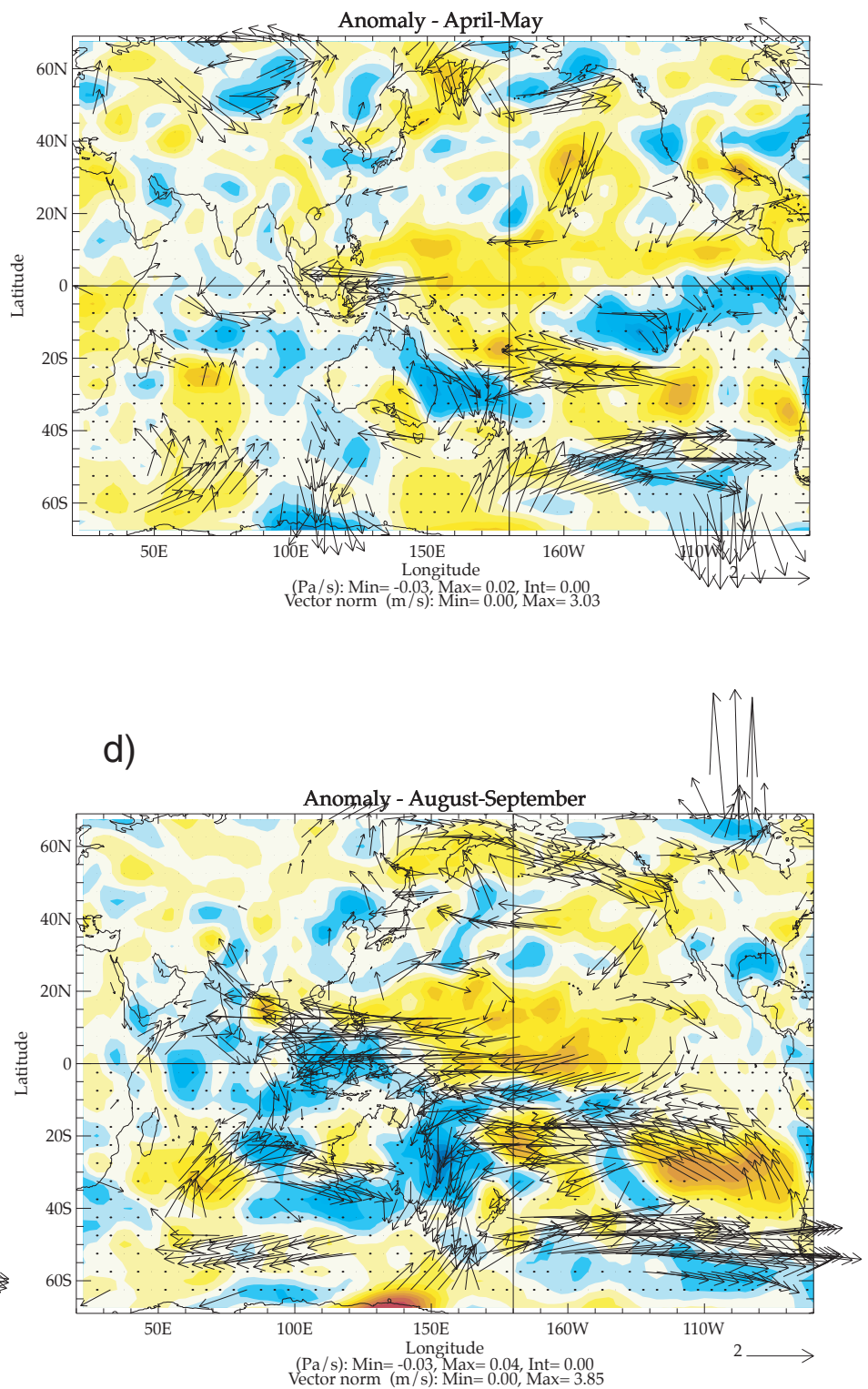

f)

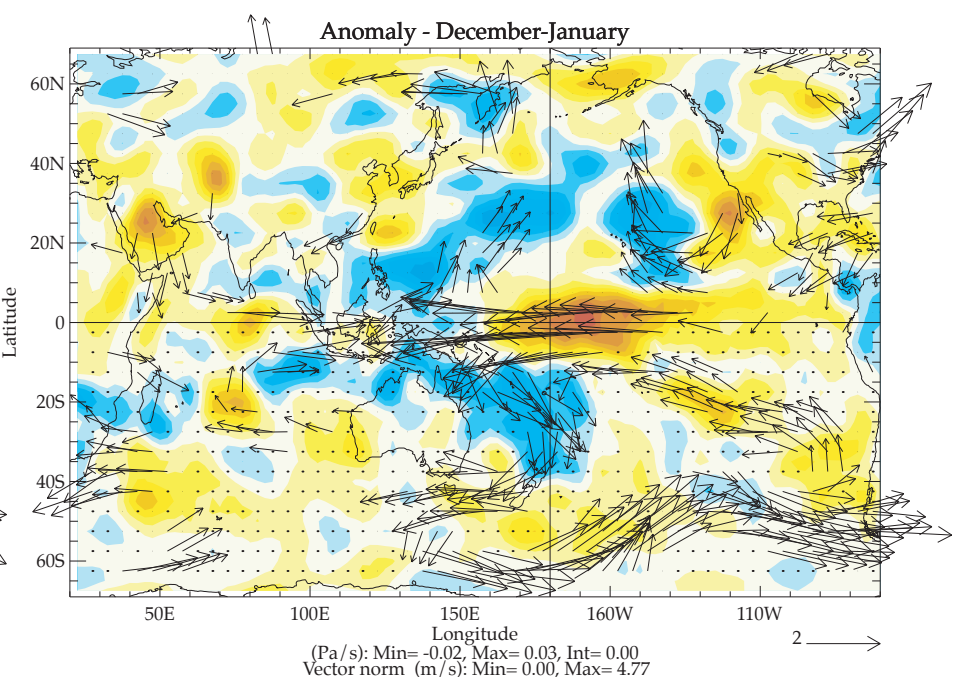




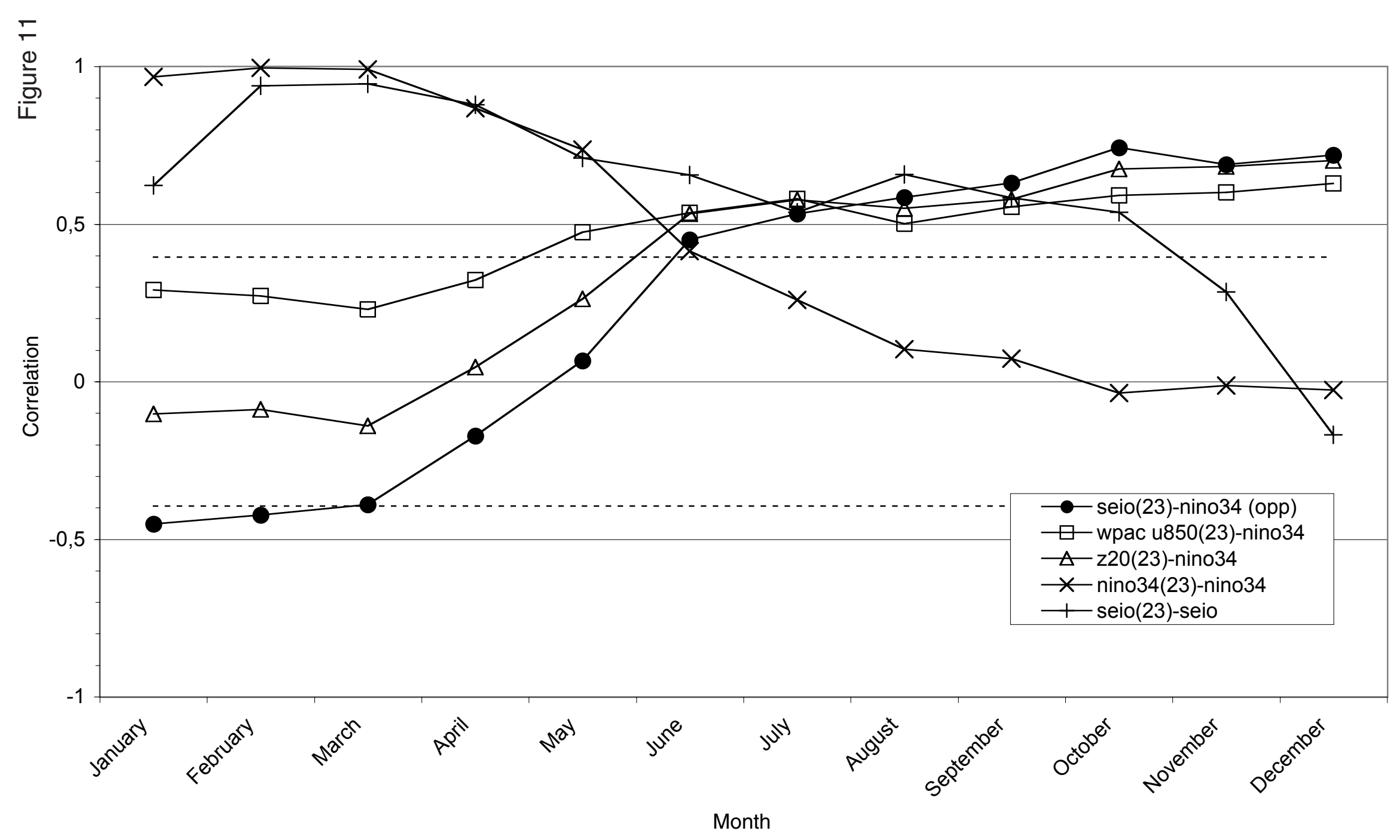




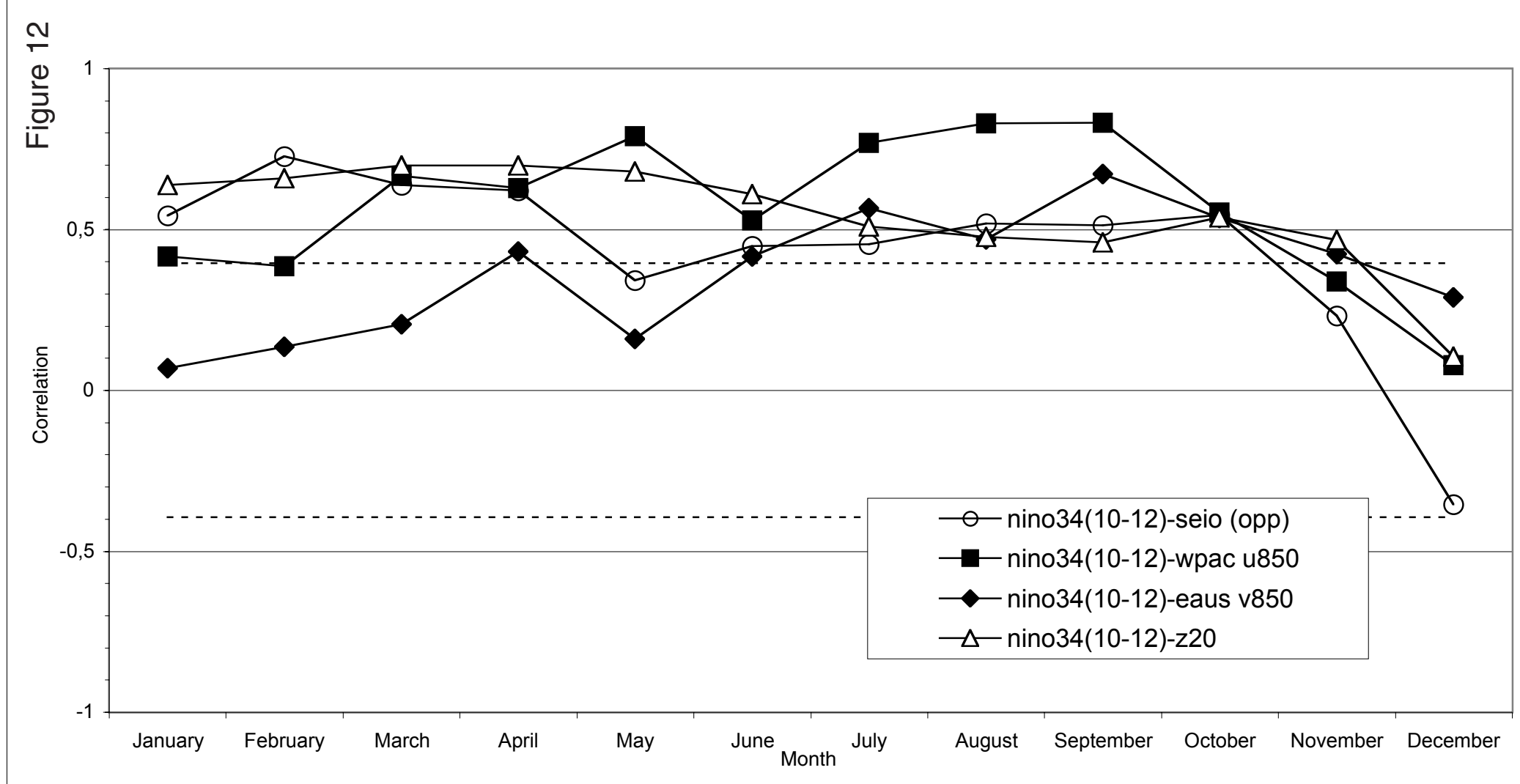




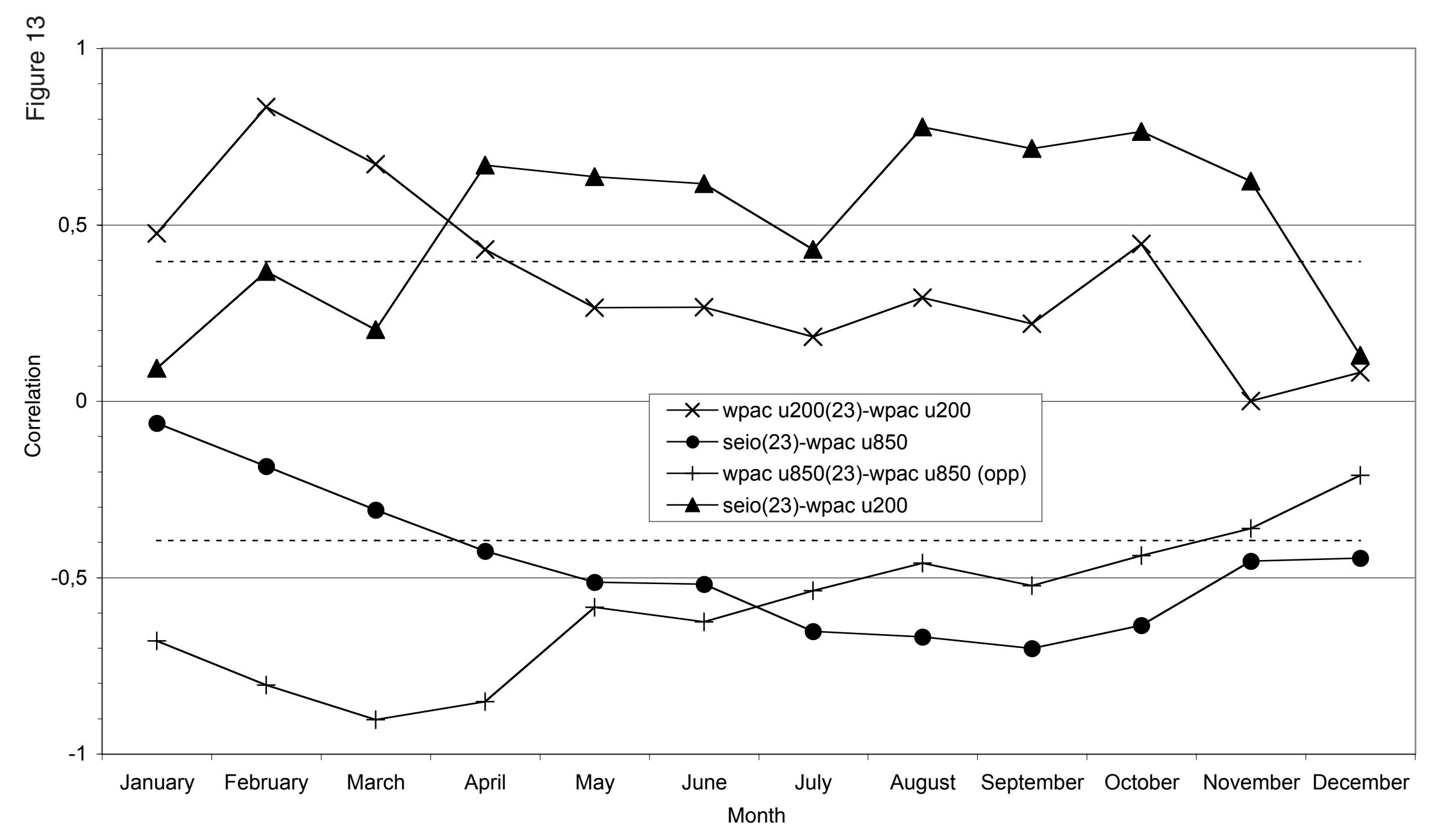




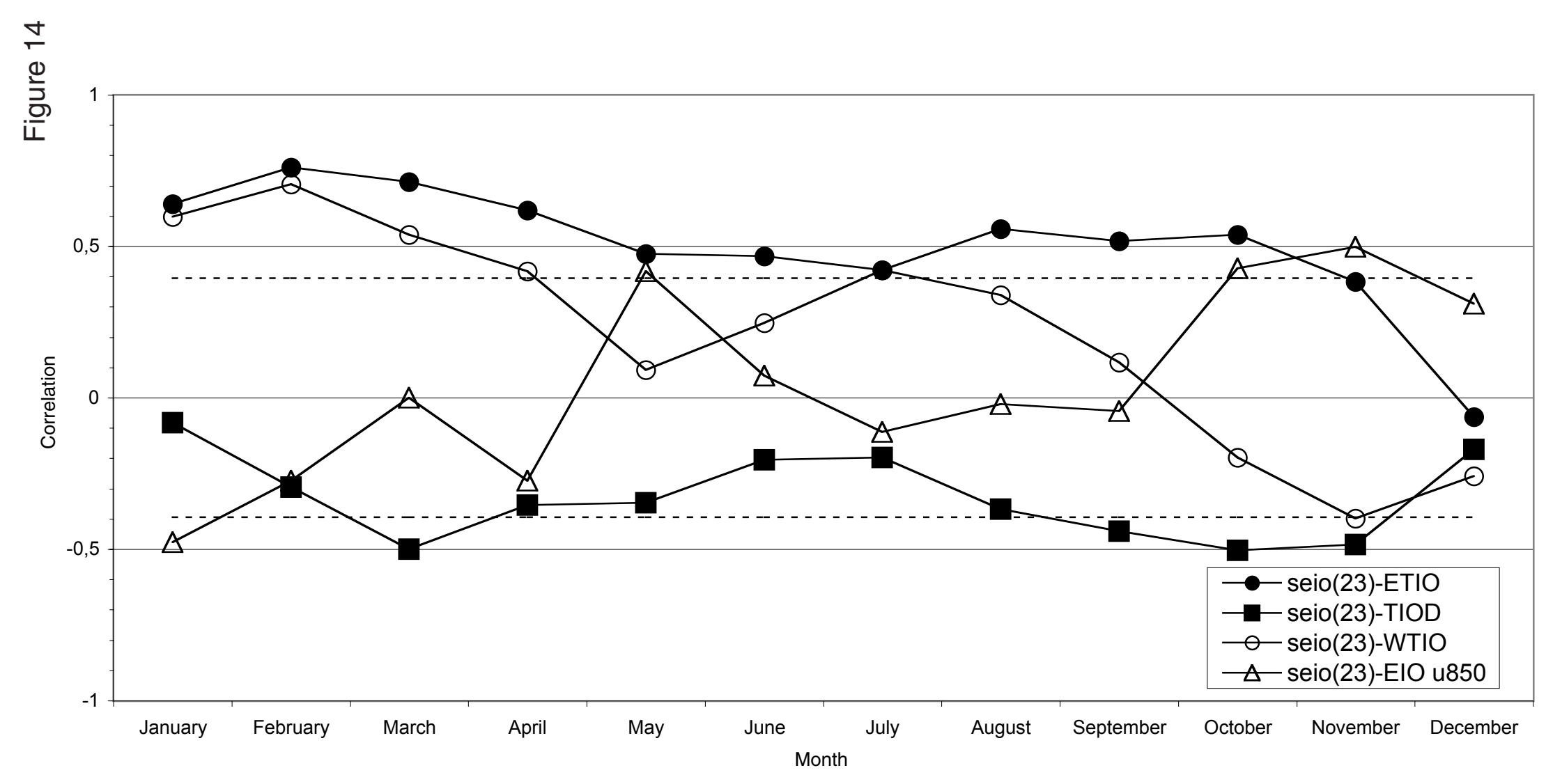

